\title{
Eleven new species of Amblypsilopus Bigot (Diptera: Dolichopodidae: Sciapodinae) and a key to the species of Madagascar and adjacent islands
}

\author{
Igor Ya. GRICHANOV \\ All-Russian Institute of Plant Protection, Podbelskogo 3, St. Petersburg, Pushkin, 196608, Russia. \\ Email: grichanov@mail.ru \\ ๑ https://orcid.org/0000-0002-7887-7668 \\ urn:lsid:zoobank.org:author:5320AD3A-92D8-4820-8091-24802F8C8C06
}

\begin{abstract}
Eleven new species of Amblypsilopus Bigot, 1888 from Madagascar are described and illustrated: A. analamazaotra sp. nov., A. andasibensis sp. nov., A. ankarana sp. nov., A. bairae sp. nov., A. fianarantsoa sp. nov., A. freidbergi sp. nov., A. friedmani sp. nov., A. leonidi sp. nov., A. marinae sp. nov., A. olgae sp. nov., and $A$. romani sp. nov. New species differ from other representatives of the genus in morphology of male surstylus and cercus mainly and male secondary sexual characters on legs. A. flavus (Vanschuytbroeck, 1962) is redescribed. Presently, ca 60 species of Amblypsilopus are known from the Afrotropical region, and 25 species are found on Madagascar. Western Indian Ocean species are associated with the Indo-Pacific A. pallidicornis group, the Pantropical A. abruptus group and the Madagascan A. stuckenbergi group of species. An identification key to males of 28 species of Madagascar and adjacent islands is compiled for the first time.
\end{abstract}

Keywords. Sciapodinae, Amblypsilopus, Madagascar, Mascarene, Afrotropical, key.

Grichanov I.Ya. 2021. Eleven new species of Amblypsilopus Bigot (Diptera: Dolichopodidae: Sciapodinae) and a key to the species of Madagascar and adjacent islands. European Journal of Taxonomy 755: 47-87.

https://doi.org/10.5852/ejt.2021.755.1399

\section{Introduction}

The sciapodine genus Amblypsilopus Bigot, 1888 is known from all realms with about 350 species worldwide, being highly diverse in the tropical belt of the Earth (Grichanov 2017). The Australasian and Oriental faunas are especially rich with ca 120 and ca 85 species, respectively. However, many tropical islands and territories are poorly studied, with many more species awaiting both collection and description (Bickel 2019). For example, the fauna of the small-sized Fiji archipelago comprises 30 mainly endemic species (Bickel 2009), while the other larger Pacific and Indian Ocean islands number only a few or several species.

The Afrotropical fauna comprises 60 species (including missing and doubtful species and doubtful records) inhabiting the whole continent and adjacent islands (Grichanov 2018; this paper). The last 
key to the then known Afrotropical species was published by Grichanov (1998). Later, six species of the genus have been described from the region (Grichanov 1999, 2003; Meuffels \& Grootaert 2007). Amblypsilopus parilis (Parent, 1931) was placed in synonymy with A. munroi (Curran, 1924) (Grichanov 1999). Amblypsilopus nubilis (Parent, 1935) and A. aenescens (Vanschuytbroeck, 1952) were transferred to the genera Dytomyia Bickel, 1994 and Ethiosciapus Bickel, 1994, respectively (Grichanov 2003).

Regarding the western Indian Ocean islands, Lamb (1922) found A. pallidicornis (Grimshaw, 1901) in the Seychelles and associated a series of females from these Islands with the Oriental A. simplex (De Meijere, 1910); the latter being a rare Javanese species (Bickel 1994) that must be excluded from the Afrotropical Region (Grichanov 1996; Meuffels \& Grootaert 2009). Amblypsilopus pallidicornis is widespread on islands of the Australasian and Oriental regions (Grichanov 1998; Meuffels \& Grootaert 2009). One more species (A. prysjonesi) was described from Seychelles (Aldabra) by Meuffels \& Grootaert (2007). Two endemic species of the genus were described from Réunion (Grichanov 2003).

The first Madagascan species of the genus (A. flabellifer) was described by Becker (1923) and has never been recorded again. Vanschuytbroeck $(1952,1957,1962)$ described three sciapodine species from Madagascar in three different genera, which were later associated with Amblypsilopus. He also reported A. rectangularis (Parent, 1937) from there (material was not found later); this doubtful species was originally described from a female from the Democratic Republic of the Congo and must be excluded from the Madagascan fauna (Grichanov 1998). Grichanov (1998, 1999, 2003) described 8 new species from Madagascar and recorded A. pallidicornis and the continental African A. cilifrons (Parent, 1937) from the Island for the first time.

Up to date, 14 species are known from Madagascar, two species from Seychelles and two species from Réunion. In this paper, 11 new species of the genus from the Republic of Madagascar are described, and a revised identification key to males of 28 species of Madagascar and adjacent islands is provided.

\section{Material and methods}

Material used in this study was borrowed from the museums listed below. The newly described species of Amblypsilopus were photographed with a ZEISS Discovery V-12 stereo microscope and an AxioCam MRc5 camera. Preparations of male genitalia were photographed with a ZEISS Axiostar stereo microscope and an AxioCam ICc3 camera. They are stored in glycerol in a microvial attached to the insect pin. Seventeen females collected in the Analamazaotra Reserve together with the males of eleven species described below are not treated here, because they lack diagnostic characters and are unrecognizable. Morphological terminology and abbreviations follow Cumming \& Wood (2017) and Grichanov \& Brooks (2017). Body length is measured from the base of the antenna to the posterior tip of epandrium. Wing length is measured from the base to the wing apex.

The types of the new species and other material are mounted on pins and housed at the following repositories

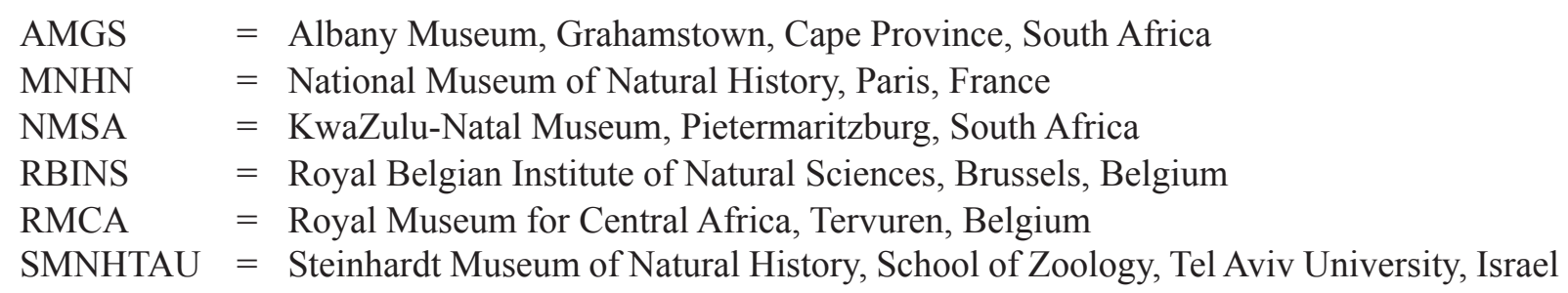




\title{
Results
}

\author{
Class Insecta Linnaeus, 1758 \\ Order Diptera Linnaeus, 1758 \\ Superfamily Empidoidea Latreille, 1804 \\ Family Dolichopodidae Latreille, 1809 \\ Subfamily Sciapodinae Becker, 1917 \\ Tribe Chrysosomatini Becker, 1918 \\ Genus Amblypsilopus Bigot, 1888
}

\section{Type species}

Psilopus psittacinus Loew, 1861 [as "psitacinus Fabricius"] (original designation).

\section{Notes}

Bickel (1994) associated the genus with the tribe Chrysosomatini. Grichanov \& Brooks (2017) provided a key to all Afrotropical genera of the subfamily Sciapodinae. See Bickel (2019) and Grichanov \& Brooks (2017) for a diagnosis of the genus. About sixty (including the new) species of Amblypsilopus are known from the Afrotropical Region. Males usually have modified and ornamented podomeres (male secondary sexual characters or MSSC) diagnostic in defining species and species groups; tarsomeres are elongated or shortened. Male surstylus and cercus are greatly variable. Females of closely related species are generally indistinguishable morphologically (e.g., Irwin 1974; Grichanov 1998).

\section{Key to species of Amblypsilopus from Madagascar and adjacent islands (males)}

1. Fore coxa yellow; halter yellow with brown knob

- Fore coxa black on at least basal half or entirely brown to black; halter black-brown (yellowish brown in A. prysjonesi)

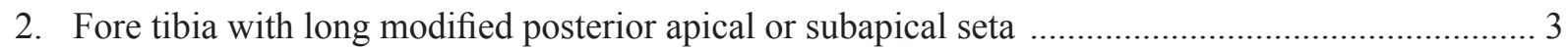

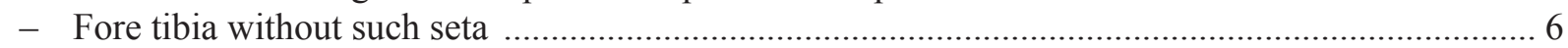

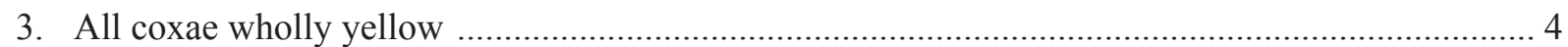

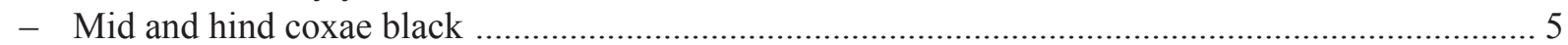

4. Antenna yellow; face broad, about three times as wide as postpedicel; fore tibia as long as basitarsus; fore basitarsus ventrally at base with cluster of very short bristles and one longer and stronger black bristle; cercus with capitate seta at middle (Hardy \& Kohn 1964: fig. 61h); 4.5-5.5 mm (Madagascar, Mahe, Praslin, Silhouette; also Oriental, Pacific islands) ............A. pallidicornis (Grimshaw, 1901)

- Antenna black; face narrow, about as wide as postpedicel; fore tibia $3 / 5$ as long as basitarsus; fore basitarsus with long white ventral hairs on basal 1/5; cercus without flagellate seta at middle (Fig. 7); $5 \mathrm{~mm}$ (Madagascar)

A. freidbergi sp. nov.

5. Fore and mid femora bare; hind femur with light ventral cilia; fore basitarsus three times as long as segment 2; cercus bifurcated, with wide lobes (Grichanov 1998: fig. 25); $4.5 \mathrm{~mm}$ (Madagascar) ....

A. bruneli Grichanov, 1998

- All femora with long dark ventral cilia; fore basitarsus two times as long as segment 2; cercus bifurcated, with thin lobes (Grichanov 1998: fig. 26); $3.8 \mathrm{~mm}$ (Madagascar)

A. dallastai Grichanov, 1998

6. All coxae wholly yellow, at most mid or hind coxa with orange spot …...................................... 7

- At least mid coxa dark brown or with blackish brown spot .......................................................... 12 
7. Mesonotum and abdomen mostly blue-green; fore tarsus simple; cercus narrow, elongate, as long as epandrium, sparsely covered with long setae dorsally and ventrally (Grichanov 1999: fig. 13); $7.25 \mathrm{~mm}$ (Madagascar)

A. kaplanae Grichanov, 1999

- Mesonotum and abdomen almost entirely yellow; some segments of fore tarsus modified or bearing elongate setae; cercus various

8. Fore basitarsus shorter than fore tibia; cercus as long as epandrium, swollen at base and bearing long setae (Fig. 12); $4.1 \mathrm{~mm}$ (Madagascar) A. romani sp. nov.

- Fore basitarsus as long as or longer than fore femur and tibia combined; cercus various 9

9. Segment 3 of fore tarsus two times as long as segment 2, with 1-2 long dorsoapical setae, longer than segment 4; segments 4 and 5 of fore tarsus flattened; cercus with 2 long dorsal setae; $3-4 \mathrm{~mm}$ (Madagascar)

A. stuckenbergi (Vanschuytbroeck, 1957)

- Segment 3 of fore tarsus as long as segment 2, without long dorsoapical setae; cercus with several short dorsal setae

10. Segments 4 and 5 of fore tarsus black; cercus with subequal in length median and ventral lobes (Fig. 9); $6.3 \mathrm{~mm}$ (Madagascar) A. leonidi sp. nov.

- At least segment 5 of fore tarsus silvery white; median (distal) lobe of cercus much longer than ventral lobe .11

11. Segment 4 of fore tarsus black and segment 5 silvery white; long lobe of cercus with 2 long setae at middle, without modified setae at apex (Fig. 2); $5.2 \mathrm{~mm}$ (Madagascar) .....A. andasibensis sp. nov.

- Segments 4 and 5 of fore tarsus white; long lobe of cercus ending with one long and one short thick setae, without long setae at middle (Fig. 11); $5.7 \mathrm{~mm}$ (Madagascar) A. olgae sp. nov.

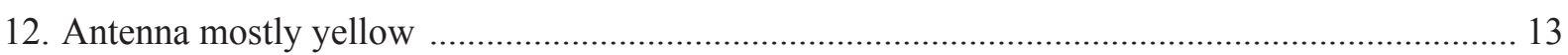

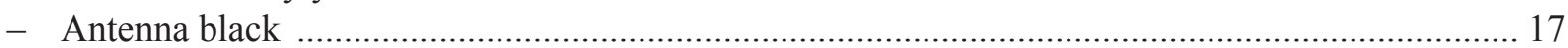

13. Mid tibia with dorsal row of erect hairs, slightly longer than tibia diameter; fore basitarsus as long as tibia, flattened; cercus simple, narrow, not longer than surstylus, with long apical seta ............ 14

- Mid tibia without dorsal pectination; other characters various ................................................... 15

14. Mid tibia except basal fifth with dorsal row of short erect cilia; fore and mid basitarsi without erect setae; ventral lobe of cercus expanded distally; apical bristle on dorsal lobe of cercus at most 1.5 times as long as other cercal setae (Grichanov 1998: fig. 27); 5-6 mm (Madagascar)

A. grootaerti Grichanov, 1998

- Mid tibia with full dorsal row of short erect hooked setae; fore and mid basitarsi with long erect setae; ventral lobe of cercus narrow to apex; apical bristle on dorsal lobe of cercus at least two times as long as other cercal setae (Fig. 10); $5.2 \mathrm{~mm}$ (Madagascar)

A. marinae sp. nov.

15. Fore basitarsus 1.5 times as long as tibia, with ventral and dorsal pectination; cercus with broad ovoid basal part and long filiform distal part (Fig. 4); $5.7 \mathrm{~mm}$ (Madagascar) .......A. bairae sp. nov.

- Fore basitarsus at least two times as long as tibia, with ventral pectination; cercus bifurcated, with long thin lobes 16

16. Fore and mid femora with anteroventral and posteroventral rows of setae, nearly as long as respective femur diameter; fore tibia and basitarsus each with group of elongate ventral setae at base, longer than podomere diameter; cercus with one bristle between lobes, nearly as long as ventral lobe (Fig. 8); 5.9 mm (Madagascar)

A. friedmani sp. nov. 
- Fore and mid femora with at most few elongate anteroventral and posteroventral setae, at most half as long as respective femur diameter; fore tibia and basitarsus without groups of elongate ventral setae at base; cercus with one bristle between lobes, half as long as ventral lobe (Fig. 6); $6.5 \mathrm{~mm}$ (Madagascar)

A. flavus (Vanschuytbroeck, 1962)

17. Mid and hind coxae black; tibia and tarsi simple, without modified setulae; segment 8 of abdomen with pair of rather long bristles in addition to short ordinary setae

- Hind coxa yellow; mid coxa coxa yellow with orange or brown spot; at least fore tibia or some tarsomeres modified, with erect ciliation; segment 8 of abdomen with short setae of equal length ..

18. Segment 8 of abdomen with pair of very long bristles; the longest bristle about three times as long as epandrium; cercus with dorsal lobe shorter than ventral lobe (Grichanov 2003: fig. 12); 4.9-5.1 mm (Réunion)

A. reunionensis Grichanov, 2003

- Segment 8 of abdomen with the longest bristle about $2 / 3$ times as long as epandrium; cercus with dorsal lobe longer than ventral lobe (Grichanov 2003: fig. 13); $4.65 \mathrm{~mm}$ (Réunion)

A. takamaka Grichanov, 2003

19. Fore tibia and tarsus with erect ciliation; fore tarsus simple in other respects, at most two times as long as fore tibia, entirely brown; cercus trilobed, with dorsal lobe with strong and long dorsal bristle at apex; surstylus large, about as large as epandrium (Grichanov 1999: fig. 12); $3.75 \mathrm{~mm}$ (Madagascar)

A. ankaratrensis Grichanov, 1999

- Fore tibia and tarsus without distinct erect ciliation; fore tarsus distinctly longer than three times fore tibia, with at least segment 5 white; cercus bilobed; surstylus trilobed, with short narrow lobes .. 20

20. Fore tarsus nearly three times as long as fore tibia, with segment 4 yellow, flattened and widened, with posterior comb of 8-9 long flattened setae; segment 2 distinctly longer than segment 3 (Fig. 5); $4.7 \mathrm{~mm}$ (Madagascar) A. fianarantsoa sp. nov.

- Fore tarsus at least 4 times as long as fore tibia, with segment 4 black, simple; segment 2 distinctly shorter than segment 3 (Fig. 1); $4.7 \mathrm{~mm}$ (Madagascar) A. analamazaotra sp. nov.

21. Hind femur mostly yellow; fore tibia with very long posterior seta at apical third or fourth; cercus trilobed, with unequal lobes; dorsal lobe of cercus with 3 very long apical bristles 22

- Hind femur mostly black or dark brown; fore tibia with or without long setae; cercus simple, with relatively short setae (Amblypsilopus abruptus species group)

22. Fore femur with yellow ciliation below; cercus with long median and short dorsal lobes (Grichanov 2003: fig. 10); $3.9 \mathrm{~mm}$ (Madagascar) A. ambila Grichanov, 2003

- Fore femur with black ciliation below; cercus with short and fused median and dorsal lobes (Grichanov 2003: fig. 11); $4.8 \mathrm{~mm}$ (Madagascar) A. ranomafana Grichanov, 2003

23. At least fore femur with long brown-black ventral bristles

- Fore femur with white ciliation below, sometimes with few dorsal or preapical black hairs, or bare

24. Fore basitarsus 1.5 times as long as segment 2; fore tibia with posteroventral row of 4-5 long fine setae on distal $2 / 3$; fore tarsomeres 1 and 2 with posterior row of elongate setae, about as long as tarsomere diameter; cercus with black hairs and setae (Fig. 3); $3.7 \mathrm{~mm}$ (Madagascar) 
- Fore basitarsus distinctly shorter than segment 2; fore tibia and tarsus devoid of long setae; cercus with short pale dorsal and dark apical hairs (see redescription of holotype in Grichanov 1998: 118); $4.5 \mathrm{~mm}$ (Madagascar) A. madagascariensis (Vanschuytbroeck, 1952)

25. Cercus long and narrow, at least twice as long as epandrium, with slightly enlarged base, thickened apex and stronger hairs on apex (Becker 1923: fig. 16); fore tibia with two ventral setae on apical half; fore basitarsus slightly widened, as long as tibia and longer than tarsomeres $2-5$ combined, with 5 strong dorsal setae; $4 \mathrm{~mm}$ (Madagascar) A. flabellifer (Becker, 1923)

- Cercus short, usually broad, not much longer than epandrium; fore tibia without conspicuous ventral setae; fore basitarsus without strong setae

26. Cercus very broad, triangular, with pointed apex (Grichanov 1998: fig. 28); fore tibia with posterior seta at apical fourth; fore basitarsus slightly widened, with ventral pile; $5.2 \mathrm{~mm}$ (Madagascar) ........

A. kraussi Grichanov, 1998

- Cercus narrow, digitiform; fore tibia without remarkable setae

27. Surstylus broad, about as long as wide, with basal seta 2 times as long as other setae; epandrial setae unequal in length (Grichanov 1998: fig. 25); 3.4-3.8 mm (Madagascar, Continental Africa)

A. cilifrons (Parent, 1937)

- Surstylus narrow, distinctly longer than wide, with basal seta not much longer than other setae; epandrial setae equal in length (Meuffels \& Grootaert 2007: fig. 5); body length: 3.0-3.2 mm (Aldabra) A. prysjonesi (Meuffels \& Grootaert, 2007)

Amblypsilopus abruptus species group

\section{Diagnosis}

See Bickel (1994) for a diagnosis of the group. The Madagascan Amblypsilopus abruptus species group shares mostly primitive characters, such as the simple cercus and surstylus, short antennae, broad face, mostly non-ornamented and non-elongated legs, unmodified wing venation, usually dark body and femora.

\section{Notes}

The Amblypsilopus abruptus group is widespread throughout the Old World tropics. The following Madagascan species belong to the A. abruptus group: A ankarana, A. cilifrons, A. flabellifer, A. kraussi, A. madagascariensis and A. prysjonesi. Amblypsilopus cilifrons is reported also from DR Congo, Kenya, Namibia, Nigeria and Togo. Amblypsilopus prysjonesi is known only from the type locality on the Seychelles islands (Aldabra).

\section{Amblypsilopus ankarana sp. nov. \\ urn:1sid:zoobank.org:act:9F936DA0-BD46-4F1A-A4F6-AFE61E667628}

Fig. 1

\section{Diagnosis}

Amblypsilopus ankarana sp. nov. belongs to the A. abruptus species group and is close to A. disjunctus (Parent, 1936) from Central Africa and to A. madagascariensis from Madagascar, which differ from the new species in the fore basitarsus 1.5 times as long as segment 2; the fore tibia and tarsus devoid of long setae. The fore basitarsus is 1.5 times as long as segment 2 in the new species; the fore tibia with posteroventral row of $4-5$ long fine setae on distal $2 / 3$; the fore tarsomeres 1 and 2 with posterior row of elongate setae, about as long as tarsomere diameter. 


\section{Etymology}

The species is named after the Ankarana Special Reserve situated in northern Madagascar, in the former Antsiranana Province, now the Diana Region. The Reserve is a small, partially vegetated plateau composed of $150 \mathrm{Ma}$ old Middle Jurassic limestone. With an average annual rainfall of about 2000 millimetres, the underlying rocks are susceptible to erosion, thereby producing caves and underground rivers. The rugged relief and the dense vegetation have helped protect the region from human intrusion (Rossi 1974).

\section{Material examined}

\section{Holotype}

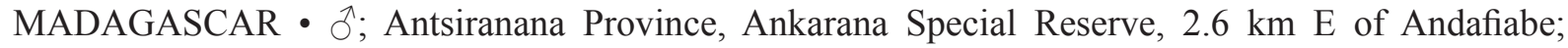
$12^{\circ} 57.523^{\prime}$ S, 4907.189' E; 4-6 Jan. 2007; A.H. Kirk-Spriggs leg.; AMGS.

\section{Description}

Male (Fig. 1A)

Measurements. Body length $3.7 \mathrm{~mm}$; antenna length $1.6 \mathrm{~mm}$; wing length $3.7 \mathrm{~mm}$; wing width $1.2 \mathrm{~mm}$.

HeAd (Fig. 1B). Frons shining greenish violet; about 10 long vertical and one long and strong postvertical bristles; upper postocular setae black, with uppermost seta rather long; lateral postocular setae white, long, uniserial; ventral postcranium covered with irregular white long hairs; face shining greenish violet, broad, bulging under antennae, 1.25 times as high as wide under antennae, 1.85 times as high as wide at clypeus, at clypeus three times as wide as postpedicel; clypeus densely covered with short white hairs, large, as high as wide; antenna (Fig. 1C) black, 2.2 times as long as height of head; scape simple; pedicel with ring of short bristles; postpedicel conoid, as long as high, with short hairs; arista-like stylus dorsoapical, separated from postpedicel, with fused segments, microscopically haired; length $(\mathrm{mm})$ of scape, pedicel, postpedicel, stylus, 0.06/0.06/0.08/1.41; proboscis and palpus black, with white hairs; palpus with 2 black bristles.

THorax. Mesonotum and scutellum metallic blue-green, pleura blue-black, weakly grey pollinose; 2 long dorsocentral bristles behind suture with strongest posterior pair and 3 shorter dorsocentrals anteriorly; 4 pairs of rather long acrostichals; scutellum with 2 strong bristles.

LEGs. Including coxae black; fore and mid coxae with mostly black hairs and 2-4 black subapical bristles; hind coxa with 3 long and about 5 short black setae; all femora with double row of long ventral setae decreasing in length distally, at most 1.5-2 times as long as diameter of femur; mid femur with 3 posteroventral subapical seta; fore tibia (Fig. 1D) with posteroventral row of 4-5 setae, two times as long as diameter of tibia; fore tarsomeres 1-2 with complete posterior row of setae, as long as diameter of segment, with ventral pad of white hairs along entire length (Fig. 1E); mid and hind tibiae with few rather short dorsal and ventral setae; hind tarsomeres 4-5 dorsoventrally flattened and slightly widened; femur, tibia and tarsomere (from first to fifth) length ratio (mm): fore leg: 0.92/0.94/0.62/0.38/0.18/0.1/0.09, mid leg: 1.08/1.25/0.96/0.3/0.2/0.13/0.1, hind leg: 1.24/1.78/0.82/0.35/0.18/0.1/0.09.

WING (Fig. 1F). Widest at middle, greyish, veins brown; costa with elongate, slightly curved setulae; $R_{4+5}$ gently curved to $M_{1}$ in apical third; $M_{1+2}$ almost straight; $M_{1}$ with strong elbow, forming nearly right angle with $M_{1+2}$; ratio of parts of costa between $R_{2+3}$ and $R_{4+5}$ to those between $R_{4+5}$ and $M_{1}, 4 / 1$; crossvein $\mathrm{dm}-\mathrm{m}$ straight; ratio of crossvein $\mathrm{dm}-\mathrm{m}$ to apical part of $\mathrm{M}_{1+2}$ (fork-handle) to apical part of $\mathrm{M}_{4}, 0.55 / 0.5 / 0.24$; anal vein weak; anal lobe and alula well developed; anal angle acute; lower calypter black, with black cilia; halter black. 


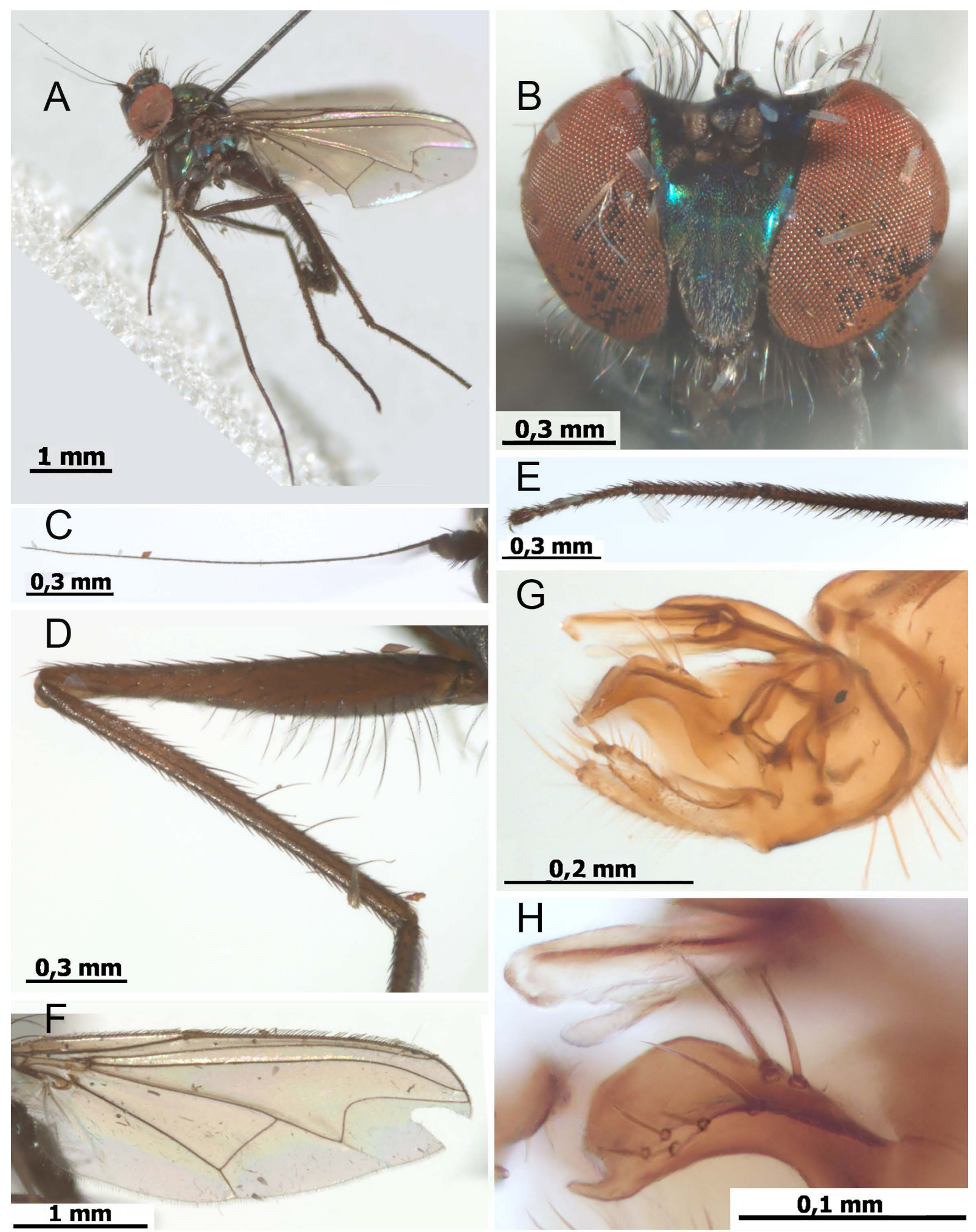

Fig. 1. Amblypsilopus ankarana sp. nov. Holotype, $\widehat{\partial}$ (AMGS). A. Habitus. B. Head. C. Antenna. D. Fore femur and tibia. E. Fore tarsus. F. Wing. G. Hypopygium, left lateral view, reflected light. H. Surstylus, ventrolateral view, transmitted light. 
AвDOMEN. Thin, shining blue-black, with long black cilia and long marginal setae; pregenital segments combined two times as long as mesonotum; hypopygium (Fig. 1G) black, with black appendages; cercus short, strap-like (dorsal view), densely haired, with 3 pedunculate bristles at apex; surstylus strongly curved, flattened and semi-rounded (ventral view), with 3 strong mid-ventral setae, 4 weaker setae distally, thin hooked dorsoapical process (Fig. 1H); epandrial lobe reduced; one short epandrial seta.

\section{Female}

Unknown.

Amblypsilopus pallidicornis species group

\section{Diagnosis}

See Bickel (1994) for a diagnosis of the group. The Madagascan Amblypsilopus pallidicornis species group shares such characters as rather broad face in males (2.5-4 times as wide as postpedicel height) and elongate antennae (about half as long as body). The other characters are very variable and unavailable for further splitting of the groups.

\section{Notes}

The Amblypsilopus pallidicornis group has a broad range throughout the Oriental and Australasian regions. The following Madagascan species belong to the A. pallidicornis group: A. ambila, A. ankaratrensis, A. bairae, A. bruneli, A. dallastai, A. flavus, A. friedmani, A. grootaerti, A. kaplanae, A marinae, A. pallidicornis, A. ranomafana, A. reunionensis, A. romani and A. takamaka. A. pallidicornis is reported also from Oriental and Pacific islands. Amblypsilopus reunionensis and A. takamaka are endemic to Réunion.

\section{Amblypsilopus bairae sp. nov. urn:1sid:zoobank.org:act:B618714C-44F2-4845-AAC7-572FDE8890DD}

Fig. 2

\section{Diagnosis}

Amblypsilopus bairae sp. nov. is close to A. flavus and A. friedmani sp. nov. in habitus. The last two species differ from $A$. bairae sp. nov. in the fore basitarsus at least two times as long as tibia and in a bifurcated cercus. Fore basitarsus 1.5 times as long as tibia in the new species; fore tibia and tarsus entirely covered with erect setulae, about as long as diameter of podomeres, somewhat longer at base of tibia and at base of basitarsus; cercus with broad and high basal part and long filiform distal part (Fig. 2F-G).

\section{Etymology}

The species name is dedicated to Baira Grichanova, mother of my grandchildren (St. Petersburg, Russia).

\section{Material examined}

\section{Holotype}

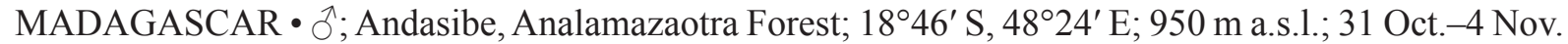
2007; A. Freidberg leg.; SMNHTAU.

\section{Description}

Male (Fig. 2A)

MEAsurements. Body length $5.7 \mathrm{~mm}$; antenna length $3.3 \mathrm{~mm}$; wing length $5.4 \mathrm{~mm}$; wing width $1.7 \mathrm{~mm}$. 
HEAD (Fig. 2B). Frons greenish blue-black, whitish pollinose; anterior vertical seta absent; long and strong postvertical bristle; upper postocular setae black, short; lateral postocular setae white, uniserial; ventral postcranium covered with irregular white long hairs; face blue-black, white pollinose, broad, 1.2 times as high as wide under antennae, 2.2 times as high as than wide at clypeus, at clypeus 2.5 times as wide as postpedicel; clypeus large, slightly bulging, as high as wide; antenna (Fig. 2C) with scape and pedicel

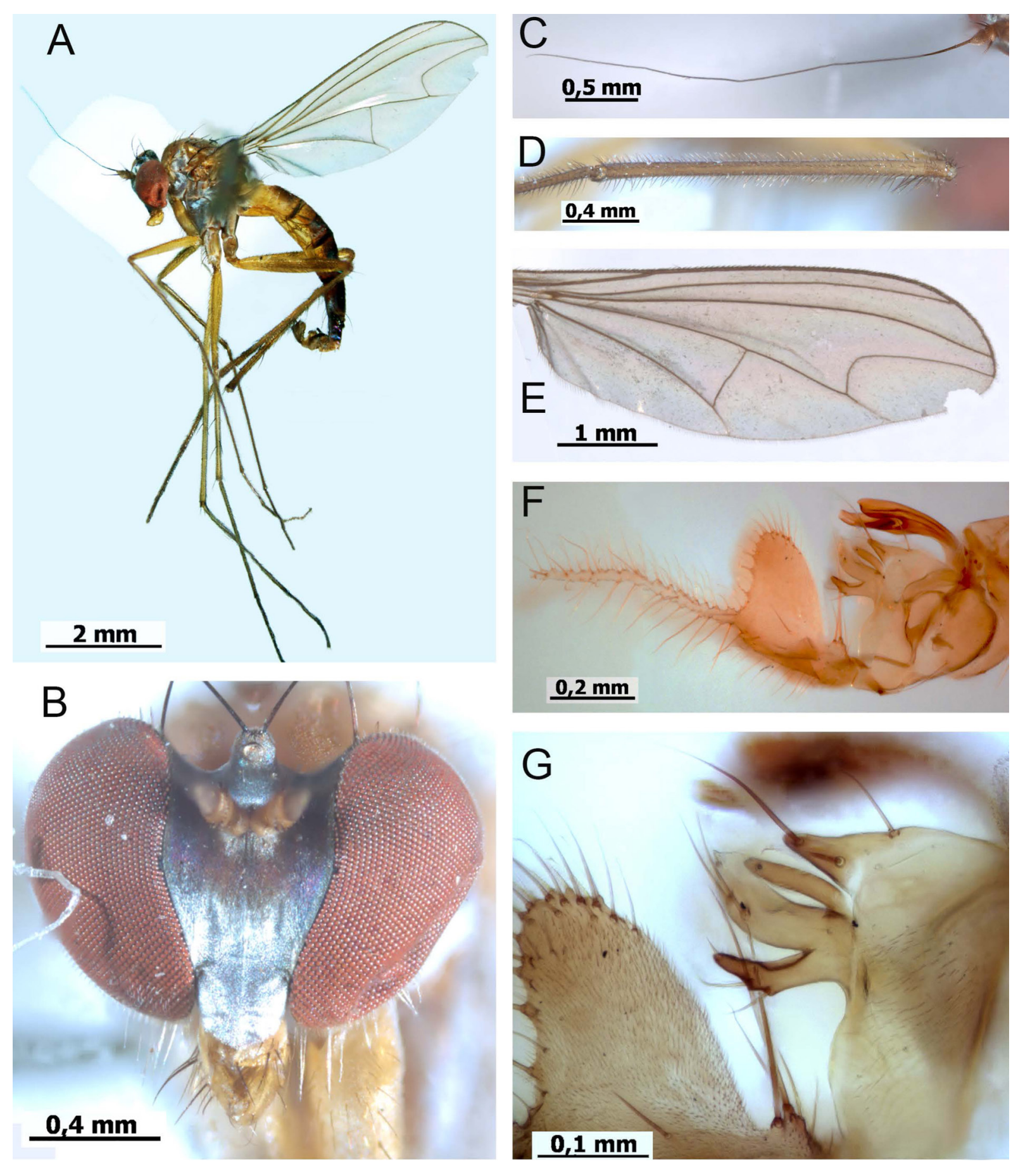

Fig. 2. Amblypsilopus bairae sp. nov. Holotype, đ̊ (SMNHTAU). A. Habitus. B. Head. C. Antenna. D. Fore tibia. E. Wing. F. Hypopygium, left lateral view, reflected light. G. Epandrial lobe, surstylus and base of cercus, lateral view, transmitted light. 
dirty yellow, postpedicel brown-black, 3.6 times as long as height of head; scape swollen; pedicel with short bristles, with one long dorsal and two long ventral bristles; postpedicel elongate-conoid, 1.25 times as long as high, with short hairs; arista-like stylus black, apical, separated from postpedicel, with fused segments, microscopically haired; length $(\mathrm{mm})$ of scape, pedicel, postpedicel, stylus, 0.09/0.08/0.15/3.03; proboscis and palpus orange, with white and black hairs; palpus with 1 black bristle.

THORax. Mesonotum orange-brown, shining, weakly pollinose; scutellum black dorsally, metallic bluish green; pleura dark brown, white pollinose; metepimeron yellow; 2 long dorsocentral bristles with strongest posterior pair, and 3 hairlike setae anteriorly; acrostichals long, biserial, gradually decreasing in size anteriorly, with posterior setae as long as penultimate dorsocentrals; scutellum with 2 strong bristles and 2 hairs laterally.

Legs. Mostly yellow or dirty yellow; coxae yellow, but mid and hind coxae brownish from outside; fore tarsus brown from tip of basitarsus; mid and hind tarsi black from tip of basitarsus; fore and mid coxae with long white and black hairs and 2-4 black subapical bristles; hind coxa with 1 black seta at middle; fore femur with anterior row of long setae on basal half, about as long as diameter of femur, and 2-3 posterior long setae at base; mid femur with posteroventral subapical seta; fore tibia (Fig. 2D) and tarsus entirely covered with erect setulae, about as long as diameter of podomeres, somewhat longer at base of tibia and at base of basitarsus; mid tibia with 2 anterodorsals and 2 posterodorsals, with 1 ventral seta; mid and hind tarsi simple, cylindrical; hind tibia with several dorsal and short ventral setae; femur, tibia and tarsomere (from first to fifth) length ratio $(\mathrm{mm})$ : fore leg: 1.78/1.88/2.51/0.78/0.7/0.46/0.21, mid leg: 1.74/2.5/2.06/0.74/0.51/0.3/0.14, hind leg: 2.13/3.34/1.49/0.85/0.43/0.14/0.1.

WING (Fig. 2E). Weakly widened distally, almost hyaline, veins brown; $\mathrm{R}_{4+5}$ gently curved to $\mathrm{M}_{1}$ in apical third; $M_{1+2}$ straight; $M_{1}$ with strong elbow, forming nearly right angle with $M_{1+2}$ and obtuse angle with $\mathrm{M}_{2}$; ratio of parts of costa between $\mathrm{R}_{2+3}$ and $\mathrm{R}_{4+5}$ to those between $\mathrm{R}_{4+5}$ and $\mathrm{M}_{1}, 3.35 / 1$; crossvein dm-m straight; ratio of crossvein dm-m to apical part of $\mathrm{M}_{1+2}$ (fork-handle) to apical part of $\mathrm{M}_{4}, 0.66 / 1.08 / 0.35$; anal vein and lobe weakly developed; anal angle obtuse; lower calypter yellow, with black cilia; halter yellow with brown knob.

AвDOMEN. Thin, mostly shining blue-green, with short black hairs and long marginal setae; segment 1 yellow, with white and dark hairs; segments 2-3 mostly orange-yellow, blackish distally; segments 4-6 black; pregenital segments combined 2.3 times as long as mesonotum; hypopygium (Fig. 2F) orange-brown, with brown appendages; cercus with short narrow neck bearing 2 very long and 2 short pedunculate setae, with broad and high basal part bearing short setae along distal and ventral margins, with long filiform distal part covered with brown-black setae along whole length and curved hairs ventrally; surstylus (Fig. 2G) projected, bilobed; dorsal arm of surstylus deeply cleft, with 3 apical and subapical setae on each lobe; ventral arm of surstylus small, finger-like, with 3 small setae apically; epandrial lobe small, triangular, with 1 basal, 1 median and 1 apical seta.

\section{Female}

Unknown.

Amblypsilopus flavus (Vanschuytbroeck, 1962)

Fig. 3

Megistostylus flavus Vanschuytbroeck, 1962: 353. Type locality: Madagascar: Ambodivoangy.

Chrysosoma flavum - Dyte \& Smith 1980: 445.

Plagiozopelma flavum - Bickel 1994: 231.

Amblypsilopus flavus - Grichanov 1998: 84. 


\section{Diagnosis}

Amblypsilopus flavus is very close to A. friedmani sp. nov. in habitus, differing from the latter species in the fore and mid femora with at most few elongate anteroventral and posteroventral setae, at most half as long as femur diameter; the fore tibia and basitarsus without groups of elongate ventral setae at base; the cercus with one bristle between lobes, half as long as ventral lobe.

\section{Material examined}

\section{Holotype}

MADAGASCAR • đ; Ambodivoangy; Dec. 1949; I. Vadon leg.; P. Vanschuytbroeck det. 1961?; Megistostylus flavus n. sp.; [ex.] Coll. Mus. Congo; MNHN.

\section{Paratype}

MADAGASCAR • 1 §̊; Ambodivoangy; Dec. 1949; I. Vadon leg.; P. Vanschuytbroeck det. 1961?; Megistostylus flavus n. sp.; Coll. Mus. Congo; MRCA.

\section{Additional material}

MADAGASCAR - 1 ठ̊; Ambodivoangy; Dec. 1949; I. Vadon leg.; P. Vanschuytbroeck det. 1950;

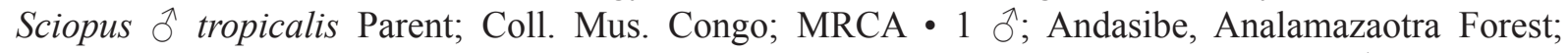
$18^{\circ} 46^{\prime}$ S, 48²4' E; 950 m a.s.1.; 31 Oct.-4 Nov. 2007; A. Freidberg leg.; SMNHTAU • 1 ơ; Ambohitra, Joffreville; 800 m a.s.1.; 9-12 Apr. 1991; A. Freidberg and Fini Kaplan leg.; SMNHTAU • 1 § (in glycerol); Fianarantsoa Province, Ranomafana Nat. Park; 19 Jan. 1952; forest; A. Pauly leg.; ex coll. RBINS.

\section{Redescription}

\section{Male}

Measurements. Body length $6.8 \mathrm{~mm}$; antenna length $5.6 \mathrm{~mm}$; wing length $6.8 \mathrm{~mm}$; wing width $1.9 \mathrm{~mm}$.

HEAD (Fig. 3A). Frons greenish blue-black, whitish pollinose; very short anterior vertical and long and strong postvertical bristles; upper postocular setae black, short; lateral postocular setae white, uniserial; ventral postcranium covered with irregular white long hairs; face blue-black, white pollinose, broad, 1.3 times as high as wide under antennae, 2.4 times as high as wide at clypeus, at clypeus 2.7 times as wide as postpedicel; clypeus large, slightly bulging, as high as wide; antenna (Fig. 3B) with scape and pedicel dirty yellow, postpedicel orange on basal half and black distally, 5 times as long as height of head; scape swollen; pedicel with short bristles, with one long dorsal and one long ventral bristles; postpedicel elongate-conoid, nearly two times as long as high, with short hairs; arista-like stylus black, apical, separated from postpedicel, with fused segments, microscopically haired; length ( $\mathrm{mm}$ ) of scape, pedicel, postpedicel, stylus, 0.09/0.1/0.21/5.33; proboscis and palpus orange, with white and black hairs; palpus with 2 black bristles.

THorax. Mesonotum and scutellum metallic bluish green, weakly pollinose; pleura bronze-green, whitish grey pollinose; metepimeron yellow; 2 long dorsocentral bristles with strongest posterior pair, and 2 hairlike setae anteriorly; acrostichals long, biserial, gradually decreasing in size anteriorly, with posterior setae as long as penultimate dorsocentrals; scutellum with 2 strong bristles and 2 minute hairs laterally.

Legs. Mostly yellow; coxae yellow, but mid coxa blackish brown from outside; fore and mid tarsi brownish to brown; hind tibia yellow to brownish; hind tarsus brown to black; fore and mid coxae with long white hairs and 2-4 black subapical bristles; hind coxa with 1 black seta at middle; femora without strong or long setae; fore femur with few ventral light hairs at base, with anterior and posterior incomplete rows of elongate setulae; mid femur with posteroventral row of elongate setulae on distal $2 / 3$; hind femur 
with few long white hairs at base; fore tibia with one short posterodorsal seta at base; fore basitarsus long, without setae; all segments with ventral rows of erect and semi-erect hairs, slightly longer than width of segments, with elongate setulae on distal apex dorsally (Fig. 3C); mid tibia with 2 anterodorsals and 3 posterodorsals, with one short ventral seta; mid and hind tarsi simple, cylindrical; hind tibia with several short dorsal and ventral setae; femur, tibia and tarsomere (from first to fifth) length ratio $(\mathrm{mm})$ : fore leg: 1.83/2.19/4.92/0.99/0.71/0.37/0.21, mid leg: 1.85/3.15/3.16/0.8/0.48/0.28/0.14, hind leg: $2.65 / 4.23 / 2.15$ $/ 1.02 / 0.63 / 0.22 / 0.16$.

WING (Fig. 3D). Widened distally, almost hyaline, veins brown; $R_{4+5}$ gently curved to $M_{1}$ in apical third; $\mathrm{M}_{1+2}$ straight in basal half, slightly convex anteriad in middle part; $\mathrm{M}_{1}$ with strong elbow, forming right angle with $M_{1+2}$; ratio of parts of costa between $R_{2+3}$ and $R_{4+5}$ to those between $R_{4+5}$ and $M_{1}, 4 / 1$; crossvein $\mathrm{dm}-\mathrm{m}$ straight; ratio of crossvein $\mathrm{dm}-\mathrm{m}$ to apical part of $\mathrm{M}_{1+2}$ (fork-handle) to apical part of $\mathrm{M}_{4}, 0.7 / 1.39 / 0.46$; anal vein and lobe reduced; anal angle absent; lower calypter yellow, with brown cilia; halter yellow with brown knob.

ABDOMEN. Thin, mostly shining blue-green, with short black hairs and long marginal setae; segment 1 yellow, with white and dark hairs; segments $2-4$ each with yellow lateral spot; pregenital segments combined two times as long as mesonotum; hypopygium (Fig. 3E) brown basally, yellow distally, with yellow appendages; cercus with broad neck covered with hairs dorsally, 2 long arms of about equal length and one long seta between arms, half as long as arms; dorsal arm of cercus filiform, with about 8 long light setae dorsally, with one very long curved subapical seta; ventral arm of cercus with several simple and flattened setae at apex, with distal process bearing large leaf-like seta; surstylus broad, projected, bilobed; dorsal arm of surstylus deeply cleft, with 2-3 apical and subapical setae on each lobe; ventral

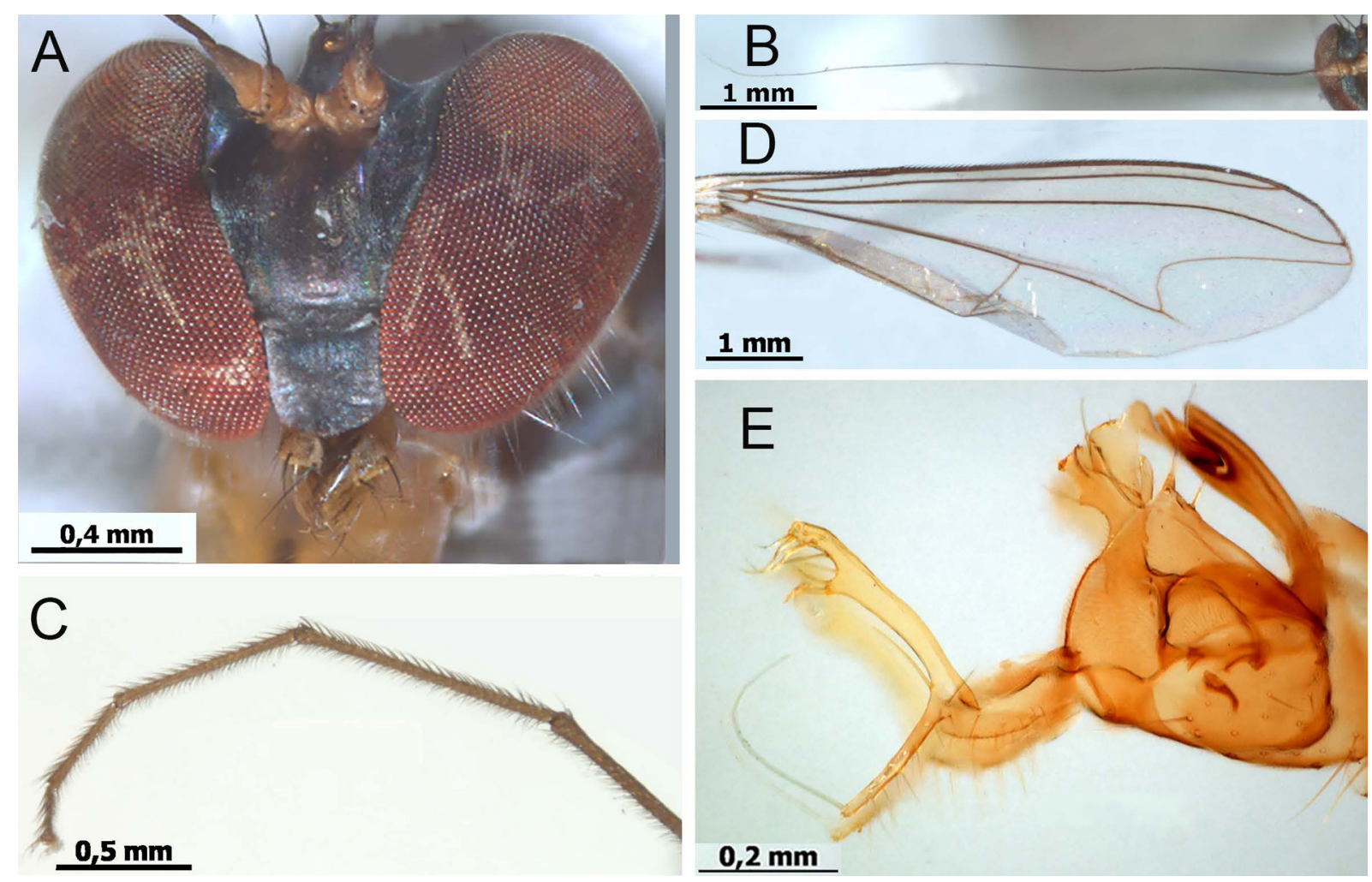

Fig. 3. Amblypsilopus flavus (Vanschuytbroeck, 1962), §, Andasibe, Analamazaotra Forest (SMNHTAU). A. Head. B. Antenna. C. Fore tarsomeres 2-5. D. Wing. E. Hypopygium, left lateral view, reflected light. 
arm of surstylus small, finger-like, with 3 small setae apically; epandrial lobe small, triangular, with 1 basal and 2 apical setae.

\section{Distribution}

Madagascar (Alaotra-Mangoro, Diana, Vatovavy-Fitovinany).

$$
\begin{aligned}
& \text { Amblypsilopus friedmani sp. nov. } \\
& \text { urn:1sid:zoobank.org:act:181E8507-D660-4EF4-92A1-56E9BEFF963D }
\end{aligned}
$$

Fig. 4

\section{Diagnosis}

Amblypsilopus friedmani sp. nov. is very close to A. flavus in habitus. The latter differs from the new species in the fore and mid femora with at most a few elongate anteroventral and posteroventral setae, at most half as long as femur diameter; the fore tibia and basitarsus without groups of elongate ventral setae at base; the cercus with one bristle between lobes, half as long as ventral lobe. Fore and mid femora of the new species are covered with anteroventral and posteroventral rows of setae, nearly as long as femur diameter; the fore tibia and basitarsus each bear group of elongate ventral setae at base, longer than podomere diameter; cercus has moderately broad neck and 2 long filiform arms and one very long seta between arms.

\section{Etymology}

The species is named for the collector of the types, Dr Leonid Friedman (SMNHTAU).

\section{Material examined}

\section{Holotype}

MADAGASCAR • đ̃'; Andasibe, Feon'Ny Ala Hôtel; [1856'49.7" S, 48²5'08.8" E]; 5 Dec. 2007;

L. Friedman leg.; SMNHTAU.

\section{Paratype}

MADAGASCAR • 1 ô; same collection data as for holotype; SMNHTAU.

\section{Description}

Male (Fig. 4A)

MEAsurements. Body length $5.9 \mathrm{~mm}$; antenna length $3.2 \mathrm{~mm}$; wing length $5.9 \mathrm{~mm}$; wing width $1.7 \mathrm{~mm}$.

HEAD (Fig. 4B). Frons greenish blue-violet, weakly pollinose; very short anterior vertical and long and strong postvertical bristles; upper postocular setae black, short; lateral postocular setae white, uniserial; ventral postcranium covered with irregular white long hairs; face greenish blue-violet, weakly pollinose, broad, 1.2 times as high as wide under antennae, 1.9 times as high as wide at clypeus, at clypeus three times as wide as postpedicel; clypeus white pollinose, large, slightly bulging, as high as wide; antenna (Fig. 4C) dirty yellow, brown at apex of postpedicel, three times as long as height of head; scape swollen; pedicel with short bristles, with one long dorsal bristle; postpedicel conoid, 1.2 times as long as high, with short hairs; arista-like stylus brown-black, apical, separated from postpedicel, with fused segments, microscopically haired; length (mm) of scape, pedicel, postpedicel, stylus, 0.09/0.07/0.13/2.87; proboscis and palpus orange, with white and black hairs; palpus with 2 black bristles.

THORAX. Mesonotum and scutellum mostly metallic bluish green, weakly pollinose; mesonotum brown on anterior slope; pleura brown-black with bronze-green reflection, grey pollinose; metepimeron yellow; 2 long dorsocentral bristles with strongest posterior pair, and 2-3 hairlike setae anteriorly; acrostichals 
long, biserial, gradually decreasing in size anteriorly, with posterior setae as long as penultimate dorsocentrals; scutellum with 2 strong bristles and 2 minute hairs laterally.

Legs. Mostly yellow; coxae yellow, but mid coxa brownish from outside; fore tarsus brown from tip of basitarsus; mid and hind tarsi black from tip of basitarsus; fore and mid coxae with long white hairs
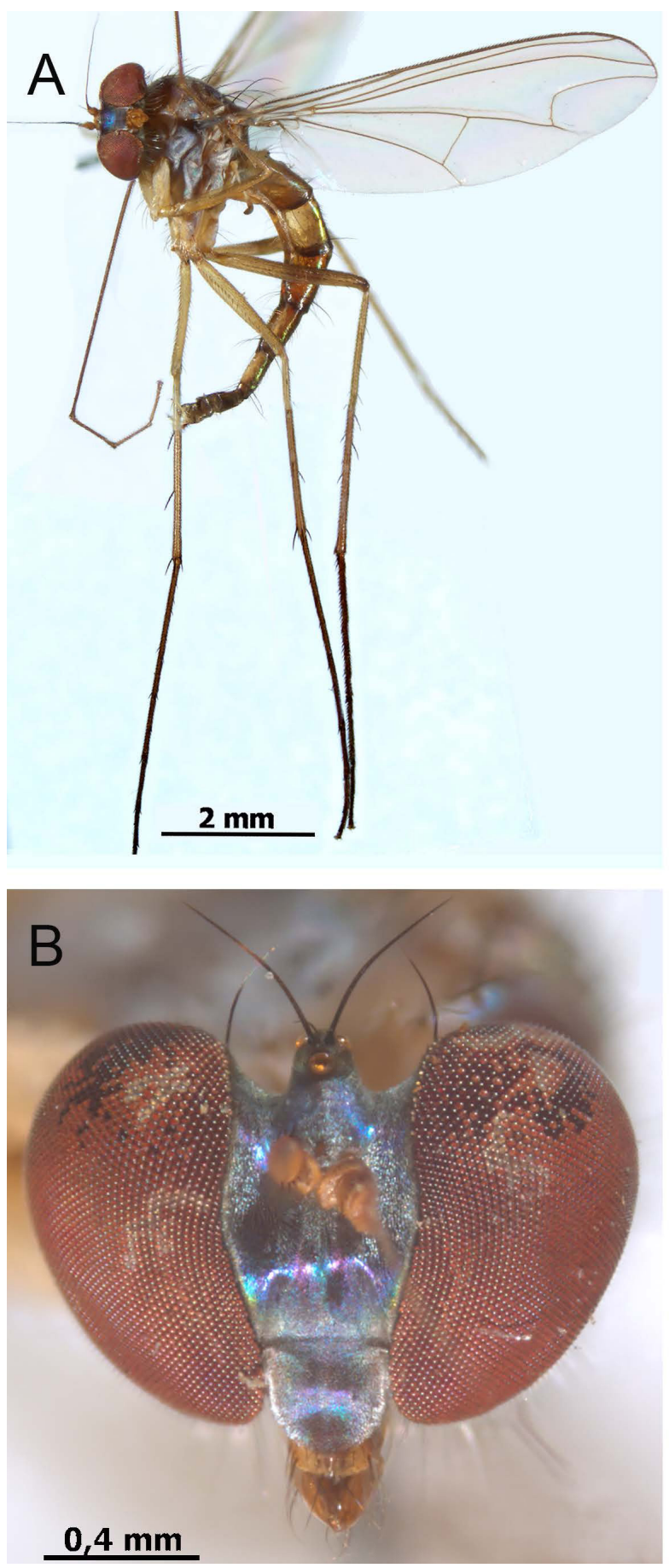
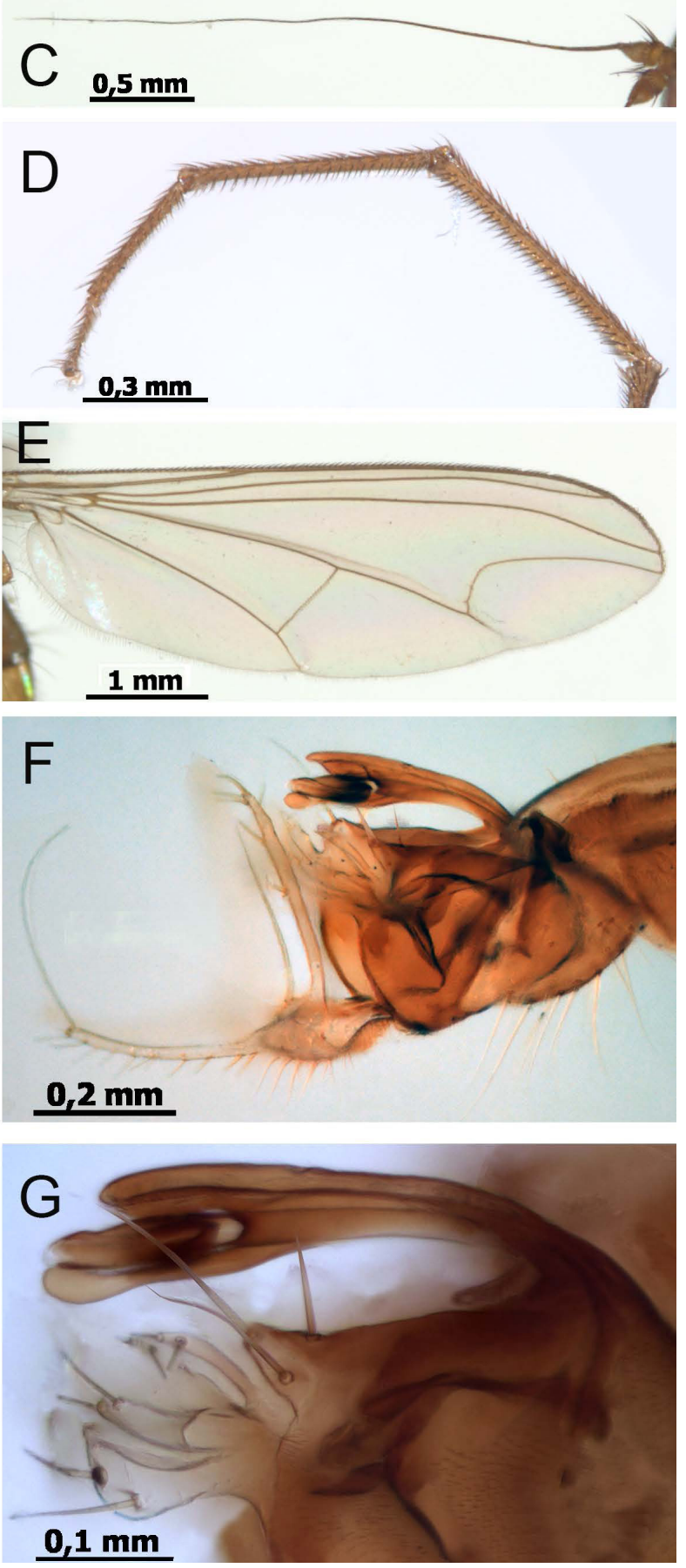

\section{$\underline{0,1} \mathrm{~mm}$}

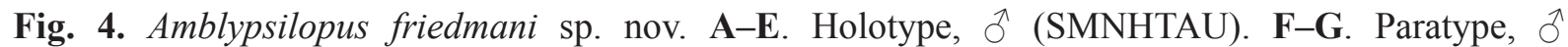
(SMNHTAU). A. Habitus. B. Head. C. Antenna. D. Fore tarsomeres 2-5. E. Wing. F. Hypopygium, left lateral view, reflected light. G. Distoventral appendages of hypopygium, transmitted light. 
and 2-4 yellow subapical bristles; mid and hind coxae with 1 black seta at middle; fore femur with anterior row of setae, at most as long as diameter of femur, and 1-2 posterior setae at base; mid femur with anterior and posteroventral rows of elongate setulae, with posteroventral subapical seta; hind femur without long hairs; fore tibia with 1 anterodorsal row of erect setulae, longer at base; fore basitarsus long, without setae; all segments of fore tarsus (Fig. 4D) with ventral rows of erect and semi-erect hairs, longer at base of basitarsus; mid tibia with 3 anterodorsals and 3 posterodorsals, without conspicuous ventral setae; mid and hind tarsi simple, cylindrical; hind tibia with several strong dorsal and short ventral setae; femur, tibia and tarsomere (from first to fifth) length ratio $(\mathrm{mm})$ : fore leg: 1.42/1.71/3.39/0.76/0.65/0.37/ 0.19, mid leg: 1.73/2.49/2.61/0.62/0.42/0.23/0.16, hind leg: 2.09/3.69/1.91/0.75/0.48/0.26/0.14.

WING (Fig. 4 E). Weakly widened distally, almost hyaline, veins brown; $R_{4+5}$ gently curved to $M_{1}$ in apical third; $M_{1+2}$ straight in basal half, slightly convex anteriad in middle part; $M_{1}$ with strong elbow, forming right angle with $\mathrm{M}_{1+2}$; ratio of parts of costa between $\mathrm{R}_{2+3}$ and $\mathrm{R}_{4+5}$ to those between $\mathrm{R}_{4+5}$ and $M_{1}, 4 / 1$; crossvein dm-m straight; ratio of crossvein dm-m to apical part of $M_{1+2}$ (fork-handle) to apical part of $\mathrm{M}_{4}, 0.74 / 1.13 / 0.37$; anal vein weak; anal lobe well developed; anal angle acute; lower calypter yellow, with brown cilia; halter yellow with brown knob.

ABDomen. Thin, mostly shining blue-green, with short black hairs and long marginal setae; segment 1 yellow, with white and dark hairs; segments $2-3$ orange, brown along distal margin; pregenital segments combined two times as long as mesonotum; hypopygium (Fig. 4F) brown, with black hypandrium and yellow cercus; cercus with moderately broad neck and 2 long filiform arms and one very long seta between arms; dorsal arm of cercus covered with light setae dorsally, with one very long apical seta; ventral arm of cercus with 5-7 short apical and subapical setae; surstylus (Fig. 4G) broad, projected, bilobed; dorsal arm of surstylus deeply cleft, with 2-3 apical and subapical setae on each lobe; ventral arm of surstylus small, finger-like, with 2 small setae apically; epandrial lobe small, triangular, with 1 basal, 1 median and 1 apical seta.

\section{Female}

Unknown.

\section{Notes}

The Feon'Ny Ala Hôtel (Fig. 13) is beside the Analamazaotra Special Reserve. The new species is collected at the damp forest edge close to hotel huts (L. Friedman, pers. com. 2020).

\section{Amblypsilopus marinae sp. nov. urn:1sid:zoobank.org:act:2FD8C8FF-FE43-43CC-B0D1-364A2AA3DCF5}

Fig. 5

\section{Diagnosis}

Amblypsilopus marinae sp. nov. is very close to A. grootaerti in habitus. The latter differs from the new species in the mid tibia with dorsal row of erect hairs except basal fifth, slightly longer than diameter of tibia; the fore and mid basitarsi without long erect setae; ventral lobe of cercus expanded distally; apical bristle on dorsal lobe of cercus at most 1.5 times as long as other cercal setae (Grichanov 1998: fig. 27). Mid tibia in the new species has a dorsal row of short erect hooked setae along entire length, nearly two times as long as diameter of tibia; the mid basitarsus bears a posterodorsal row of fine curved erect setae along entire length, ending with a small leaf-like seta; segments 2-3 of mid tarsus each with posterodorsal row of 5 small leaf-like setae; segment 4 with 2 leaf-like setae; ventral lobe of cercus narrow to apex; apical bristle on dorsal lobe of cercus at least two times as long as other cercal setae. 


\title{
Etymology
}

The species name is dedicated to Marina Grichanova, mother of my grandsons (St. Petersburg, Russia).

\section{Material examined}

\section{Holotype}

MADAGASCAR • ô; $^{\prime}$ Andasibe, Analamazaotra Forest; $18^{\circ} 46^{\prime}$ S, $48^{\circ} 24^{\prime}$ E; 950 m a.s.1.; 31 Oct.-4 Nov. 2007; A. Freidberg leg.; SMNHTAU.

\section{Paratypes}

MADAGASCAR $・ 3 \hat{\partial} \widehat{\partial}$; same collection data as for holotype; SMNHTAU.

\section{Description}

\author{
Male (Fig. 5A)
}

MEASUREMENTS. Body length $5.2 \mathrm{~mm}$; antenna length $2.7 \mathrm{~mm}$; wing length $4.7 \mathrm{~mm}$; wing width $1.3 \mathrm{~mm}$.

HEAD (Fig. 5B). Frons greenish blue-violet, weakly pollinose; short and strong anterior vertical and long and strong postvertical bristles; upper postocular setae black, short; lateral postocular setae white, uniserial; ventral postcranium covered with irregular white long hairs; face greenish blue-violet, weakly pollinose, broad, 1.4 times as high as wide under antennae, 2.2 times as high as wide at clypeus, at clypeus 2.5 times as wide as postpedicel; clypeus shining, large, slightly bulging, as high as wide; antenna (Fig. 5 C) dirty yellow, brownish at apex of postpedicel, three times as long as height of head; scape swollen; pedicel with short bristles, with one long dorsal bristle; postpedicel conoid, 1.5 times as long as high, with short hairs; arista-like stylus black, brownish at base, apical, separated from postpedicel, with fused segments, microscopically haired; length $(\mathrm{mm})$ of scape, pedicel, postpedicel, stylus, $0.11 / 0.08 / 0.15 / 2.33$; proboscis and palpus orange, with white and black hairs; palpus with 2 black bristles.

THorax. Mesonotum and scutellum mostly metallic bluish green, weakly pollinose; pleura brownblack with bronze-green reflection, grey pollinose; metepimeron yellow; 3 long dorsocentral bristles behind suture with strongest posterior pair; acrostichals short, biserial, decreasing in size anteriorly, with strongest posterior pair at suture; scutellum with 2 strong bristles and 2 minute hairs laterally.

LEGS. Mostly yellow; coxae yellow, but mid coxa brown from outside; fore tarsus with brownish basitarsus and black segment 5 ; mid and hind tarsi with black segment 5 ; fore and mid coxae with mostly black hairs and 2-4 black subapical bristles; mid and hind coxae with 1 black seta at middle; fore femur with several anteroventral setae at base, at most as long as diameter of femur, and row of posterodorsal setae on basal half decreasing in length distally with 2 basal setae two times as long as diameter of femur; mid femur with anteroventral row of elongate setulae, with posteroventral subapical seta; hind femur without long hairs; fore tibia devoid of setulae on dorsal surface, with posterior row of elongate setulae, longer at base; fore basitarsus long, thin and covered with microscopic setulae on basal half except base, with rows of erect setae at base and on distal half, two times as long as diameter of basitarsus; segments $2-5$ with rows of short erect and semi-erect hairs (Fig. 5D); mid tibia with posterodorsal row of fine curved setae along entire length, nearly two times as long as diameter of tibia, without conspicuous ventral setae; mid basitarsus with posterodorsal row of fine curved setae along entire length, ending with small leaf-like seta; segments 2-3 each with posterodorsal row of 5 small leaf-like setae; segment 4 with 2 leaf-like setae (Fig. 5E); hind tibia with several short dorsal and ventral setae; hind tarsus simple, cylindrical; hind basitarsus with 3 posteroventral rows of short flattened setulae on basal third; femur, tibia and tarsomere (from first to fifth) length ratio (mm): fore leg: 1.41/1.56/1.81/0.49/0.61/0.29/0.18, mid leg: 1.47/2.97/1.43/0.54/0.4/0.22/0.15, hind leg: 2.04/3.17/1.09/0.7/0.41/0.27/0.17. 
WING (Fig. 5F). Weakly widened distally, almost hyaline, veins brown; $R_{4+5}$ gently curved to $M_{1}$ in apical third; $M_{1+2}$ straight in basal half, slightly convex anteriad in middle part; $M_{1}$ with strong elbow, forming right angle with $\mathrm{M}_{1+2}$; ratio of parts of costa between $\mathrm{R}_{2+3}$ and $\mathrm{R}_{4+5}$ to those between $\mathrm{R}_{4+5}$ and $\mathrm{M}_{1}, 5 / 1$; crossvein dm-m straight; ratio of crossvein dm-m to apical part of $\mathrm{M}_{1+2}$ (fork-handle) to apical

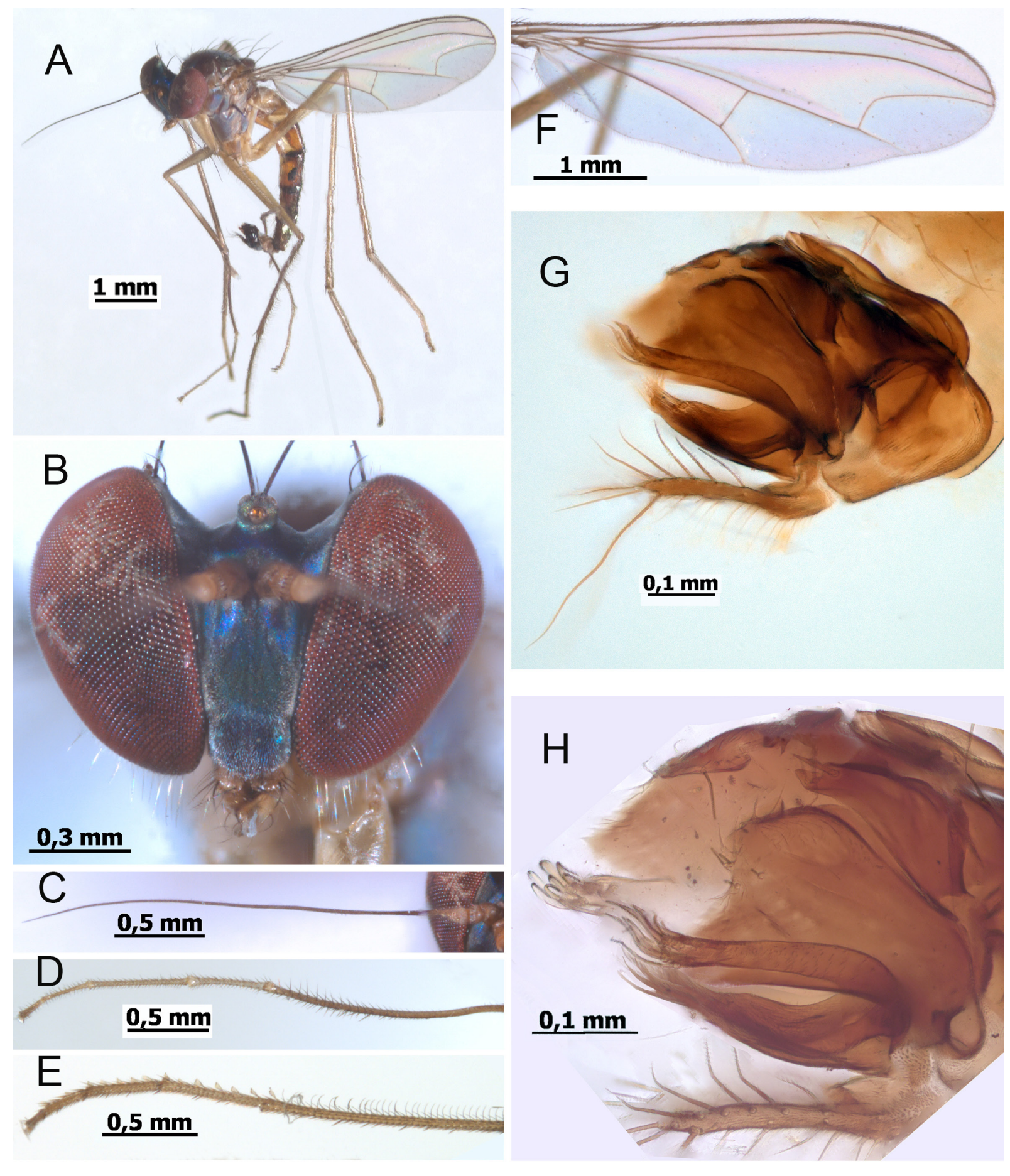

Fig. 5. Amblypsilopus marinae sp. nov. A-F. Holotype, $\partial$ (SMNHTAU). G-H. Paratype, $\partial$ (SMNHTAU). A. Habitus. B. Head. C. Antenna. D. Fore tarsus. E. Mid tarsus. F. Wing. G. Hypopygium, left lateral view, reflected light. H. Cercal lobes and surstylus, transmitted light. 
part of $\mathrm{M}_{4}, 0.4 / 1.03 / 0.38$; anal vein fold-like; anal lobe well developed; anal angle right; lower calypter yellow, with brown cilia; halter yellow with brown knob.

AвDOMEN. Thin, mostly shining blue-green, with short black hairs and long marginal setae; segment 1 dirty yellow, with white and black hairs; segments $2-3$ orange, brown along distal margin; pregenital segments combined two times as long as mesonotum; hypopygium (Fig. 5G) black, with black appendages; cercus bifurcated from base; dorsal arm nearly as long as epandrium, thin, slightly widened at base, covered with long hairs dorsally, with lateral row of 6 long black setae on distal half, with 1 extremely long black subapical dorsal seta, longer than cercus (Fig. 5H); inner lobes of ventral arms of cerci fused to apex, having distinct suture; ventral arm of each cercus trilobed (dorsal view), with broad triangular median lobe and thin and long inner and outer lobes; each lobe bearing 2-4 strong apical setae; surstylus projected, bilobed, with large flat leaflike arms expanding distally; dorsal arm of surstylus larger than ventral arm, with wide distal emargination and few short marginal setae; ventral arm of surstylus with one long seta inserted in small emargination at apex and few short marginal hairs; epandrial lobe small, elongate-triangular, with ventral seta; 2 long epandrial setae at base of epandrial lobe.

\section{Female}

Unknown.

$$
\begin{aligned}
& \text { Amblypsilopus romani sp. nov. } \\
& \text { urn:1sid:zoobank.org:act:3E431D86-C254-44BB-B5E5-E25745BCE437 }
\end{aligned}
$$

Fig. 6

\section{Diagnosis}

Amblypsilopus romani sp. nov. keys to A. stuckenbergi, differing from this and other close species in the fore basitarsus distinctly shorter than fore tibia; cercus as long as epandrium, at base swollen and bearing long setae. The fore basitarsus is as long as or longer than the fore femur and tibia combined; and the cercus is distinctly elongate and setose in A. stuckenbergi and other close species of the group.

\section{Etymology}

The species name is dedicated to Roman Grichanov, one of my grandsons (St. Petersburg, Russia).

\section{Material examined}

\section{Holotype}

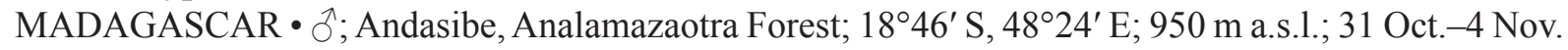
2007; A. Freidberg leg.; SMNHTAU.

\section{Paratypes}

MADAGASCAR・2 $\curvearrowright$; same collection data as for holotype; SMNHTAU.

\section{Description}

Male (Fig. 6A)

Measurements. Body length $4.1 \mathrm{~mm}$; antenna length $2.5 \mathrm{~mm}$; wing length $3.8 \mathrm{~mm}$; wing width $1.1 \mathrm{~mm}$.

HeAd (Fig. 6B). Frons black (lateral view), white pollinose; strong short anterior vertical and long postvertical bristles; upper postocular setae black, short; lateral postocular setae white, uniserial; ventral postcranium covered with irregular white hairs; face black, densely white pollinose, broad, 1.5 times as high as wide under antennae, 2.7 times as high as wide at clypeus, at clypeus nearly 4 times as wide as postpedicel; clypeus small, slightly bulging; antenna (Fig. 6C) yellow, 2.8 times as long as 

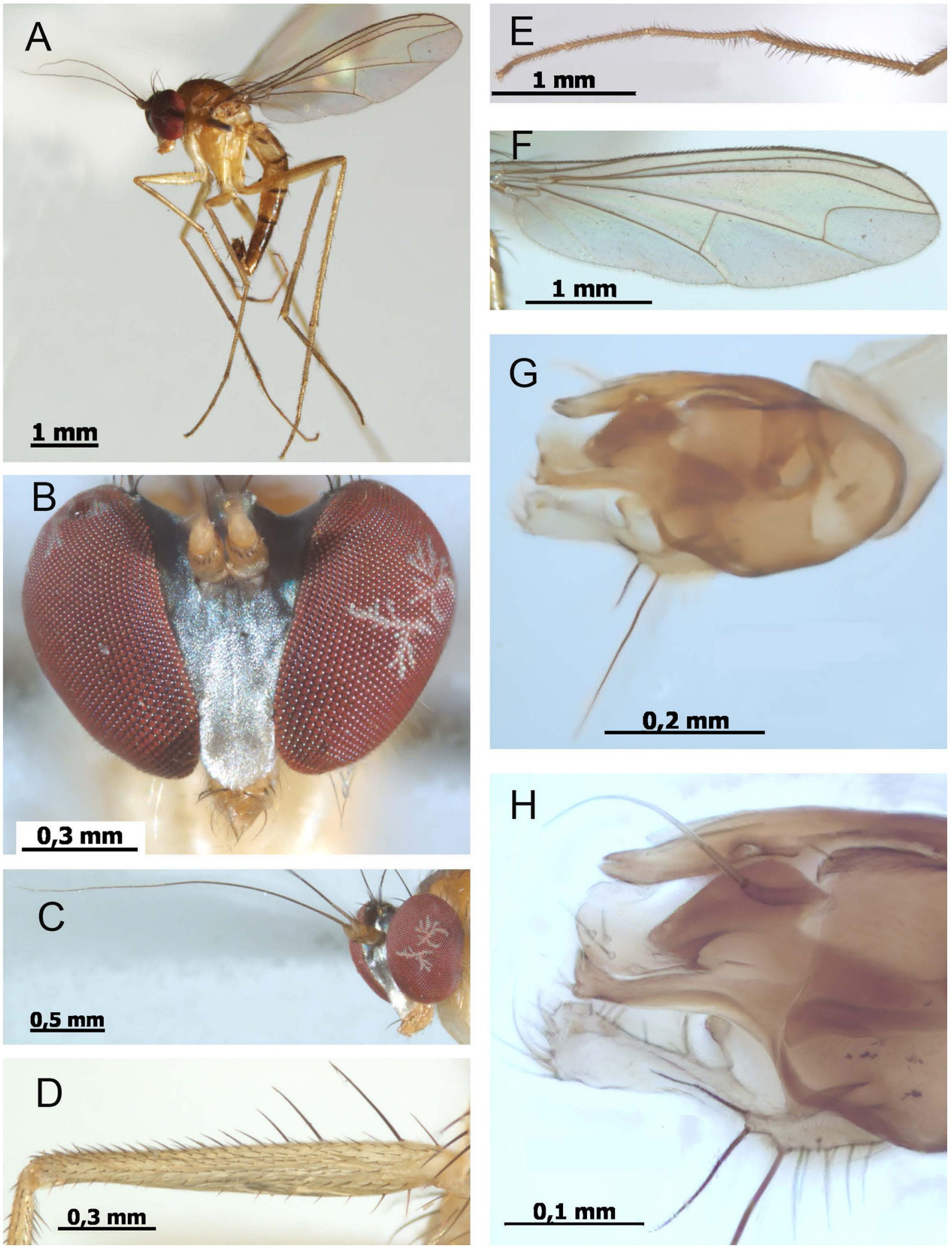

Fig. 6. Amblypsilopus romani sp. nov. A-F. Holotype, $\widehat{\partial}$ (SMNHTAU). G-H. Paratype, $ð$ (SMNHTAU). A. Habitus. B. Head, frontal view. C. Head and antenna, frontolateral view. D. Fore femur. E. Fore tarsus. F. Wing. G. Hypopygium, left lateral view, reflected light. H. Distal appendages of hypopygium, transmitted light. 
height of head; pedicel with short bristles, with one long dorsal bristle; postpedicel conoid, 1.5 times as long as high, with short hairs; arista-like stylus black, brown at base, apical, microscopically haired; length $(\mathrm{mm})$ of scape, pedicel, postpedicel, stylus, 0.06/0.06/0.12/2.23; proboscis yellow; palpus small, orange-yellow with white hairs and 2 black setae.

THORax. Mesonotum orange, with brown, shining greenish blue, medial stripe expanding posteriorly; scutellum metallic blue; pleura yellow, weakly pollinose; 6 dorsocentral bristles with strongest posterior pair and 4 hair-like setae anteriorly; acrostichals biserial, decreasing in size anteriorly, with rather strong posterior pair behind suture; scutellum with 2 strong bristles and 2 hairs laterally.

Legs. Yellow; segment 5 of all tarsi black; fore and mid coxae with dark hairs and 2-3 black subapical bristles; hind coxa with 1 black bristle at middle; fore femur with 2-3 strong dorsal bristles on basal half, 1.5-2 times as long as femur height, with few anteroventral and posteroventral strong setae at base (Fig. 6D); fore tibia and tarsus with complete rows of semi-erect setae except ventral side, with longer and stronger setae on distal $1 / 3$ of tibia and basal $1 / 3$ of basitarsus, longer than diameter of podomere (Fig. 6E); mid tibia with two anterodorsals and one very short posterodorsal, without conspicuous ventral setae; mid and hind tarsi simple, cylindrical; hind tibia with several short dorsal and ventral setae; femur, tibia and tarsomere (from first to fifth) length ratio $(\mathrm{mm})$ : fore leg: 1.33/1.49/1.21/0.61/ 0.48/0.23/0.14, mid leg: 1.3/1.94/1.38/0.49/0.33/0.18/0.1, hind leg: $1.58 / 2.5 / 0.81 / 0.54 / 0.29 / 0.22 / 0.09$.

WING (Fig. 6F). Widest at middle, almost hyaline, veins brown; $\mathrm{R}_{4+5}$ gently curved to $\mathrm{M}_{1}$ in apical third; $M_{1+2}$ almost straight; $M_{1}$ with strong elbow, forming right angle with $M_{1+2}$; ratio of parts of costa between $\mathrm{R}_{2+3}$ and $\mathrm{R}_{4+5}$ to those between $\mathrm{R}_{4+5}$ and $\mathrm{M}_{1}, 5 / 1$; crossvein dm-m straight; ratio of crossvein dm-m to apical part of $\mathrm{M}_{1+2}$ (fork-handle) to apical part of $\mathrm{M}_{4}, 0.38 / 0.88 / 0.32$; anal vein foldlike, anal lobe developed; anal angle right; lower calypter brownish yellow, with fine brown cilia; halter yellow with brown knob.

ABDOMEN. Elongate, with short black hairs and marginal setae; tergite 1 yellow; tergites $2-4$ each yellow, with narrow brown band along distal margin; tergites 5-6 brown; pregenital segments combined 2.1 times as long as mesonotum; hypopygium (Fig. 6G) dark brown, with brown appendages; cercus brownish yellow, covered with brownish hairs, somewhat longer at rounded apex, with 3 long black dorsal setae at base, longer than cercus; cerci fused at base, shorter than epandrium; hypandrium asymmetrical, with narrow left lateral arm, arising near base of hypandrium; phallus with dorsal angle; surstylus (Fig. 6H) projected, bilobed, with long thin arms of equal length; dorsal arm of surstylus widened at apex, with 2 short dorsoapical setae; ventral arm of surstylus with 5-6 simple long outer setae; epandrial lobe large, leaf-like, sclerotized, with pointed apex bearing few short setae; small fingerlike epandrial lobe at base of large lobe with one very long and one short seta at apex; one short epandrial ventral seta at base of epandrial lobes.

\section{Female}

Unknown.

\section{Amblypsilopus stuckenbergi species group}

\section{Diagnosis}

The Madagascan Amblypsilopus stuckenbergi species group shares such characters as relatively narrow male face (0.5-2.2 times as wide as postpedicel height) and relatively short antennae $(1 / 5-1 / 3$ the length of their entire bodies). The other characters are very variable and unavailable for further splitting of the groups, being sometimes found in species of the A. pallidicornis group (e.g., a long apicoventral bristle on the fore tibia). 


\title{
Notes
}

The Amblypsilopus stuckenbergi group is endemic to Madagascar. The following species belong to this group: A. analamazaotra, A. andasibensis, A. fianarantsoa, A. freidbergi, A. leonidi, A. olgae and A. stuckenbergi.

\section{Amblypsilopus analamazaotra sp. nov. urn:1sid:zoobank.org:act:5AEAE000-F228-4D8D-B537-887690037C13}

Fig. 7

\section{Diagnosis}

The new species is very close to $A$. fianarantsoa sp. nov., differing distinctly in its longer fore tarsus with segment 4 black and simple, segment 2 distinctly shorter than segment 3. Amblypsilopus fianarantsoa sp. nov. differs from the new species in the fore tarsomere 4 yellow, flattened and widened, with posterior comb of 8-9 long flattened setae, segment 2 as long as segment 3 . The fore basitarsus is $2-3$ times as long as fore tibia, and the last segment of the fore tarsus is white in both species.

\section{Etymology}

The species is named after the Analamazaotra Special Reserve, a wildlife reserve of Madagascar, which is part of Andasibe-Mantadia National Park. The reserve is situated in the region Alaotra-Mangoro, close to Moramanga and Andasibe.

\section{Material examined}

\section{Holotype}

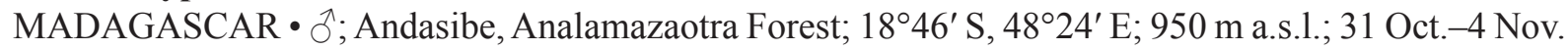
2007; A. Freidberg leg.; SMNHTAU.

\section{Paratype}

MADAGASCAR • 1 o ; same collection data as for holotype; SMNHTAU.

\section{Description}

\author{
Male (Fig. 7A)
}

Measurements. Body length $4.7 \mathrm{~mm}$; antenna length $1 \mathrm{~mm}$; wing length $3.6 \mathrm{~mm}$; wing width $1 \mathrm{~mm}$.

HEAD (Fig. 7B). Frons greenish black, white pollinose; strong anterior vertical and postvertical bristles; upper postocular setae black, short; lateral postocular setae white, uniserial; ventral postcranium covered with irregular white hairs; face densely silvery-white pollinose, narrow, under antennae 1.5 times as wide as postpedicel, at clypeus almost obliterated; clypeus small, slightly bulging; antenna (Fig. 7C) black, 2.2 times as long as height of head; pedicel with short bristles, with one long dorsal bristle; postpedicel rounded, as long as high, with short hairs; arista-like stylus dorsal, microscopically haired; length $(\mathrm{mm})$ of scape, pedicel, postpedicel, stylus (segments 1 and 2), 0.06/0.06/0.09/0.03/0.71; proboscis orange; palpus blackish, with white and brown hairs.

THorax. Mesonotum and scutellum metallic blue-green, weakly pollinose; pleura bronze-green, grey pollinose; metepimeron yellow; 6 dorsocentral bristles gradually decreasing in size anteriorly with strongest posterior pair; acrostichals short, biserial; scutellum with 2 strong bristles and 2 minute hairs laterally.

Legs. Mostly yellow; coxae yellow, but mid coxa orange at base; fore and mid tarsi brownish to brown; segment 5 of fore tarsus silvery white (Fig. 7D); hind femur brown on distal half dorsally; 

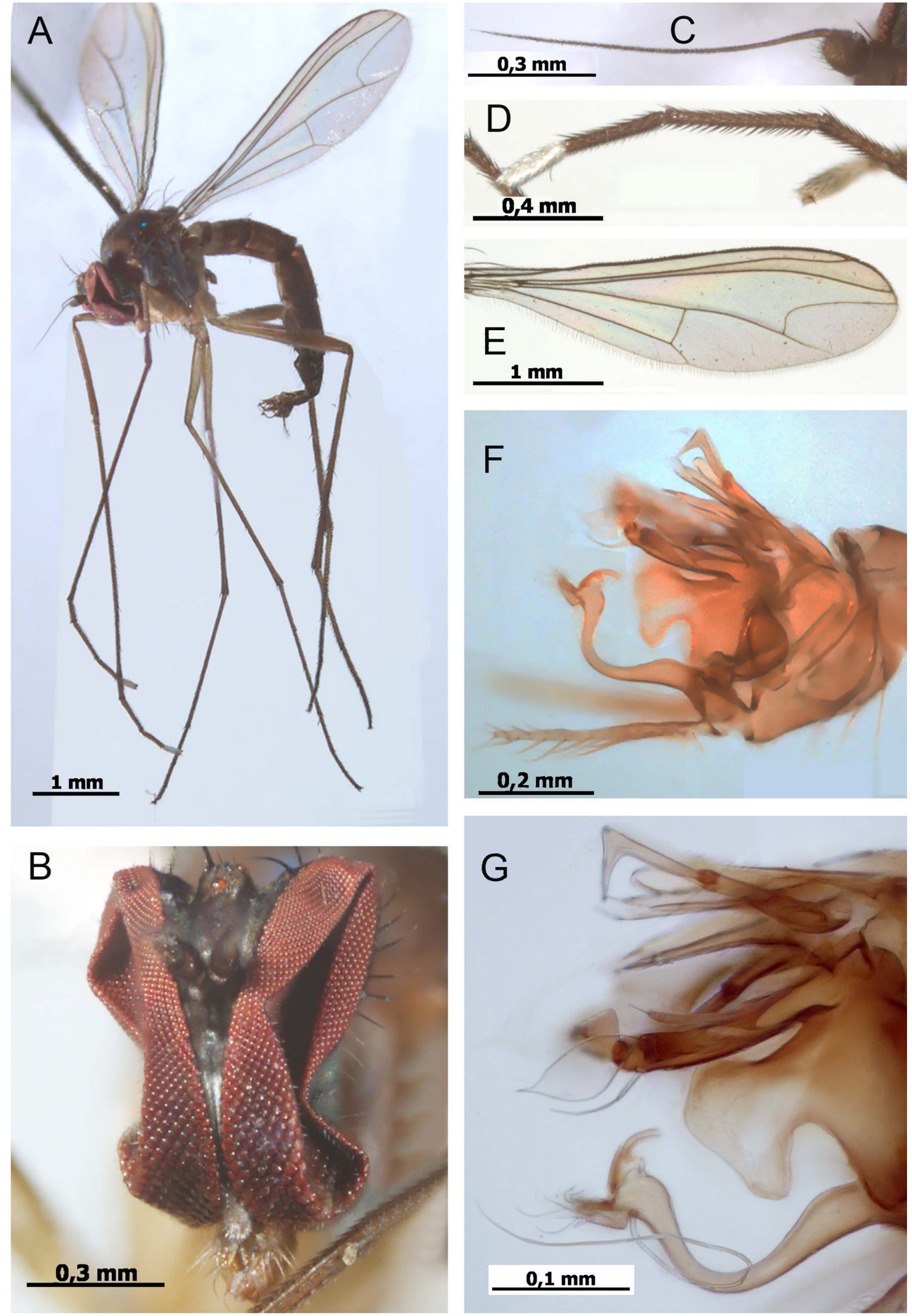

Fig. 7. Amblypsilopus analamazaotra sp. nov. A-E. Holotype, § (SMNHTAU). F-G. Paratype, ð (SMNHTAU). A. Habitus. B. Head. C. Antenna. D. Fore tarsomeres 2-5. E. Wing. F. Hypopygium, left lateral view, reflected light. G. Distoventral appendages of hypopygium, transmitted light. 
hind tibia brownish; hind tarsus brown to black; fore and mid coxae with dark hairs and 2 black subapical setae; hind coxa with 1 black seta at middle; femora without strong or long setae; fore tibia without conspicuous setae; fore basitarsus long, with 3-4 short ventral setae on distal half; mid tibia with 1-2 short anterodorsals and 2 short posterodorsals, without conspicuous ventral setae; mid and hind tarsi simple, cylindrical; hind tibia with several short dorsal and ventral setae; femur, tibia and tarsomere (from first to fifth) length ratio (mm): fore leg: 1.11/1.1/2.92/0.26/0.48/0.32/0.24, mid leg: 1.19/2.14/1.64/0.5/0.31/0.2/0.14, hind leg: 1.57/2.64/1.05/0.57/0.26/0.18/0.14.

WING (Fig. 7E). Widened distally, almost hyaline, veins brown; $R_{4+5}$ gently curved to $M_{1}$ in apical third; $\mathrm{M}_{1+2}$ straight in basal half, slightly convex anteriad in middle part; $\mathrm{M}_{1}$ with strong elbow, forming right angle with $\mathrm{M}_{1+2}$; ratio of parts of costa between $\mathrm{R}_{2+3}$ and $\mathrm{R}_{4+5}$ to those between $\mathrm{R}_{4+5}$ and $\mathrm{M}_{1}, 4 / 1$; crossvein dm-m straight; ratio of crossvein dm-m to apical part of $\mathrm{M}_{1+2}$ (fork-handle) to apical part of $\mathrm{M}_{4}, 30 / 78 / 21$; anal vein and lobe reduced; anal angle absent; lower calypter brownish, with fine yellow cilia; halter yellow with brown knob.

AвDOMEN. Thin and long, mostly shining dark brown, with short black hairs and marginal setae; segment 1 mostly yellow, with white and dark hairs; pregenital segments combined nearly three times as long as mesonotum; hypopygium (Fig. 7F) brown, with brown appendages; cercus brown, bifurcated from base; dorsal arm as long as epandrium, filiform, slightly widened at base, sparsely covered with long light setae along entire length decreasing in length distally, densely covered with hairs at base; ventral arm of cercus S-shaped, narrow, thickened at base and at apex, with two thick apical setae, one very long curved seta at base of small apicodorsal process covered with 5 short and long hairs (Fig. 7G); ventral arms of cerci fused almost to apex; surstylus projected, bilobed; dorsal arm of surstylus leaf-like, broad, with deep distal emargination; ventral arm of surstylus trilobed, with apical setae on each lobe, with oval leaf-like seta on outer lobe, with short leaf-like triangular seta and tuft of short hairs at apex of median lobe; epandrial lobe projected, trilobed; each lobe narrow, with pair of long or short flattened setae at apex; outer lobe with 1 simple and 1 hooked seta (Fig. 7G).

Female

Unknown.

Amblypsilopus andasibensis sp. nov. urn:lsid:zoobank.org:act:EF68C2DC-2411-4736-B379-563FB79470CB

Fig. 8

\section{Diagnosis}

Amblypsilopus andasibensis sp. nov. is very close to A. olgae sp. nov. in habitus. The latter differs from $A$. andasibensis sp. nov. in the fore tarsomeres $4-5$ white. The fore tarsomere 4 is entirely black in $A$. andasibensis sp. nov.; the long lobe of the cercus has 2 long setae at the middle, but no modified setae at the apex.

\section{Etymology}

The species is named after the Andasibe-Mantadia National Park located about $150 \mathrm{~km}$ east of Antananarivo, consisting principally of primary growth forest of the Alaotra-Mangoro Region in eastern Madagascar. The park's two component parts are Mantadia National Park and Analamazoatra Reserve (Newsome \& Hassell 2014). 


\section{Material examined}

\section{Holotype}

MADAGASCAR • $\mathrm{O}^{\wedge}$; Andasibe, Analamazaotra Forest; $18^{\circ} 46^{\prime} \mathrm{S}, 48^{\circ} 24^{\prime}$ E; 950 m a.s.1.; 31 Oct. 4 Nov. 2007; A. Freidberg leg.; SMNHTAU.

\section{Description}

Male (Fig. 8A)

MeAsurements. Body length $5.2 \mathrm{~mm}$; antenna length $1.1 \mathrm{~mm}$; wing length $4.5 \mathrm{~mm}$; wing width $1.2 \mathrm{~mm}$.

HEAD (Fig. 8B). Frons black, white pollinose; strong short anterior vertical and long postvertical bristles; upper postocular setae black, short; lateral postocular setae white, uniserial; ventral postcranium covered with irregular white hairs; face densely silvery-white pollinose, narrow, 3.3 times as high as wide under antennae, 7 times as high as wide at clypeus, at clypeus as wide as postpedicel; clypeus small, slightly bulging; antenna (Fig. 8C) 1.3 times as long as height of head, with scape and pedicel dirty yellow, postpedicel brown; pedicel with short bristles, with one long dorsal bristle; postpedicel ovate, 1.2 times as long as high, with short hairs; arista-like stylus black, brown at base, dorsal, microscopically haired; length $(\mathrm{mm})$ of scape, pedicel, postpedicel, stylus, 0.07/0.07/0.1/0.91; proboscis and palpus orange; palpus with brown hairs, 2 black setae.

ThORAX. Mesonotum orange, with brown, shining greenish blue, medial stripe slightly expanding posteriorly; scutellum metallic blue; pleura yellow, weakly pollinose; 6 strong dorsocentral bristles gradually decreasing in size anteriorly with strongest posterior pair; acrostichals short, biserial; scutellum with 2 strong bristles and 2 hairs laterally.

Legs. Mostly yellow; coxae yellow; segment 4 of fore tarsus black, segment 5 silvery white (Fig. 8D); last segments of mid and hind tarsi brown; fore and mid coxae with light and dark hairs and 2-3 black subapical setae; hind coxa with 1 black seta at middle; femora without strong or long setae; fore tibia without conspicuous setae; fore basitarsus thin and long, with 1 rather short basoventral seta; segment 4 cylindrical; segment 5 flattened dorsoventrally, slightly widened; segments 4-5 with white flattened setae laterally, slightly longer than tarsomere width; with black setulae dorsally; mid tibia with one short anterodorsal and two short posterodorsals (broken), without conspicuous ventral setae; mid and hind tarsi simple, cylindrical; hind tibia with several short dorsal and ventral setae; femur, tibia and tarsomere (from first to fifth) length ratio (mm): fore leg: 1.19/1.63/3.82/0.58/0.54/0.24/0.15, mid leg: 1.51/2.23/2.15/0.58/0.4/0.23/0.15, hind leg: 1.55/2.63/1.53/0.63/0.36/0.25/0.13.

WING (Fig. 8E). Widened distally, almost hyaline, veins brown; $R_{4+5}$ gently curved to $M_{1}$ in apical third; $M_{1+2}$ straight in basal half, slightly convex anteriad in middle part; $M_{1}$ with strong elbow, forming right angle with $\mathrm{M}_{1+2}$; ratio of parts of costa between $\mathrm{R}_{2+3}$ and $\mathrm{R}_{4+5}$ to those between $\mathrm{R}_{4+5}$ and $\mathrm{M}_{1}, 5 / 1$; crossvein dm-m straight; ratio of crossvein dm-m to apical part of $\mathrm{M}_{1+2}$ (fork-handle) to apical part of $\mathrm{M}_{4}, 0.37 .1 .03 / 0.33$; anal vein and lobe reduced; anal angle absent; lower calypter yellow, with fine brown-black cilia; halter yellow with brown knob.

AbDomen. Thin and long, mostly orange-yellow, brown along distal margin of tergites $2-5$, with short black hairs and marginal setae; pregenital segments combined 2.4 times as long as mesonotum; segment 7 short, symmetrical (dorsal view); tergite 7 flat, with proximal angular emargination (dorsal view); sternite 7 distinct, embracing long and thin tergite 8 ; sternite 8 symmetrical, rounded, with short setae; hypopygium (Fig. 8F) black, with brown appendages; epandrial foramen located almost symmetrically on basoventral side of epandrium; hypandrium short, with reduced arms; cercus (Fig. 8G) brown, trifurcated from base; dorsal lobe flat, elongate-triangular, half as long as epandrium, with pointed apex, sparsely covered with dark setae on outer side, densely covered with microscopic hairs on inner 

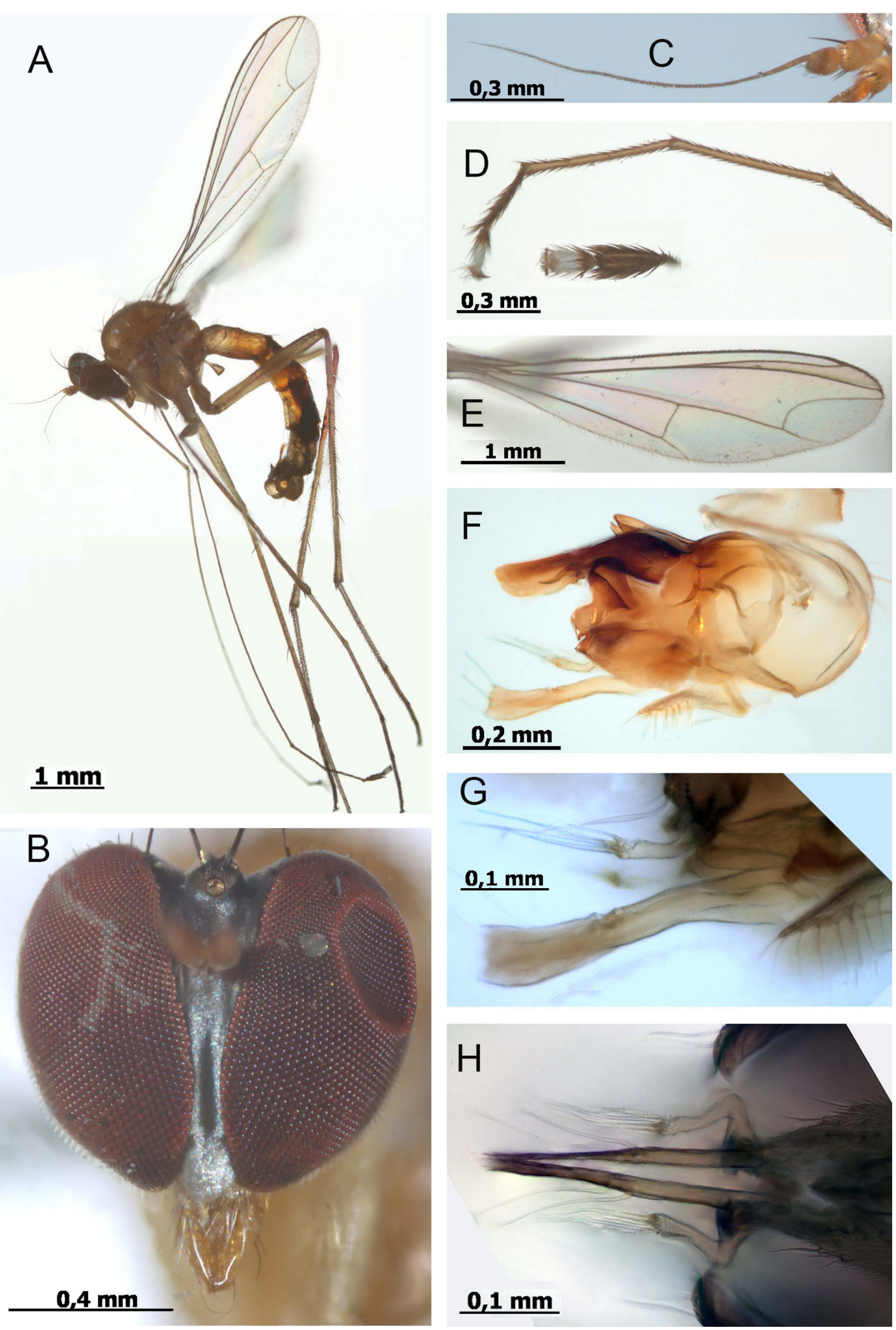

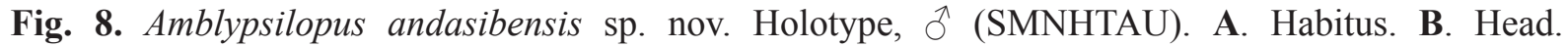
C. Antenna. D. Fore tarsomeres 2-5, lateral view, with inset showing segments 4-5, dorsal view. E. Wing. F. Hypopygium, left lateral view, reflected light. G. Cercal lobes, lateral view, transmitted light. H. Cercal lobes, dorsal view, transmitted light. 
side; middle arm of cercus (Fig. 8H) as long as epandrium, stick-shaped, flattened laterally, with 2 very long lateral setae at distal third; ventral arm of cercus strongly curved, finger-like, reaching to middle of middle arm, with small comma-like sclerotized process at base and 4 long apical setae; surstylus projected, bilobed, with irregularly curved broad flat arms; dorsal arm of surstylus pointed at apex, with one very long apical seta, with few short setae; ventral arm of surstylus with deep distal emargination, with 4 small modified setae on distoventral apex; epandrial lobe strongly projected distally, sclerotized, broad at base, narrow distally, with 2 fine epandrial setae at base (Fig. 8F).

\title{
Female
}

Unknown.

\author{
Amblypsilopus fianarantsoa sp. nov. \\ urn:lsid:zoobank.org:act:FE9D5C2E-788B-4263-8CC9-88E435DFA465
}

Fig. 9

\section{Diagnosis}

Amblypsilopus fianarantsoa sp. nov. is very close to A. analamazaotra sp. nov. in habitus. The latter differs from $A$. fianarantsoa sp. nov. in the fore tarsomere 4 black and simple, segment 2 half as long as segment 3 . The fore tarsus has segment 4 yellow, flattened and widened in the new species, with posterior comb of 8-9 long flattened setae, segment 2 as long as segment 3 . The fore basitarsus is $2-3$ times as long as the fore tibia, and the last segment of the fore tarsus is white in both species.

\section{Etymology}

The species is named after the former Fianarantsoa Province in the southeastern part of Madagascar, where the Ranomafana National Park is situated (65 km southwest of Fianarantsoa city), now in the regions of Haute Matsiatra and Vatovavy-Fitovinany. With more than 41600 hectares of tropical rainforest, the Park is home to many rare species of flora and fauna. It is part of the World Heritage Site Rainforests of the Atsinanana.

\section{Material examined}

Holotype

MADAGASCAR • $\mathrm{O}^{\top}$; Andasibe, Analamazaotra Forest; $18^{\circ} 46^{\prime} \mathrm{S}, 48^{\circ} 24^{\prime}$ E; $950 \mathrm{~m}$ a.s.1.; 31 Oct. 4 Nov. 2007; L. Friedman leg.; SMNHTAU.

\section{Paratype}

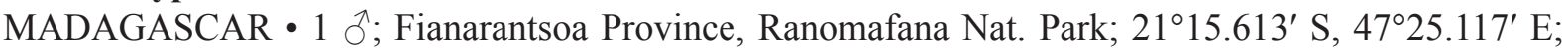
15-17 Jan. 2007; A.H. Kirk-Spriggs leg.; AMGS.

\section{Description}

Male (Fig. 9A)

Measurements. Body length $4.7 \mathrm{~mm}$; antenna length $1 \mathrm{~mm}$; wing length $4 \mathrm{~mm}$; wing width $1.1 \mathrm{~mm}$.

HEAD (Fig. 9B). Frons greenish black, white pollinose; strong anterior vertical and postvertical bristles; upper postocular setae black, short; lateral postocular setae white, uniserial; ventral postcranium covered with irregular white hairs; face densely silvery-white pollinose, narrow, under antennae two times as wide as postpedicel, at clypeus nearly equal in width to postpedicel; clypeus small, slightly bulging; antenna (Fig. 9C) black, slightly longer than height of head; pedicel with short bristles, with one long dorsal bristle; postpedicel rounded, inconspicuously longer than high, with short hairs; arista-like stylus dorsal, microscopically haired; length $(\mathrm{mm})$ of scape, pedicel, postpedicel, stylus, 0.06/0.07/0.1/0.84; proboscis orange; palpus blackish, with white and black hairs. 

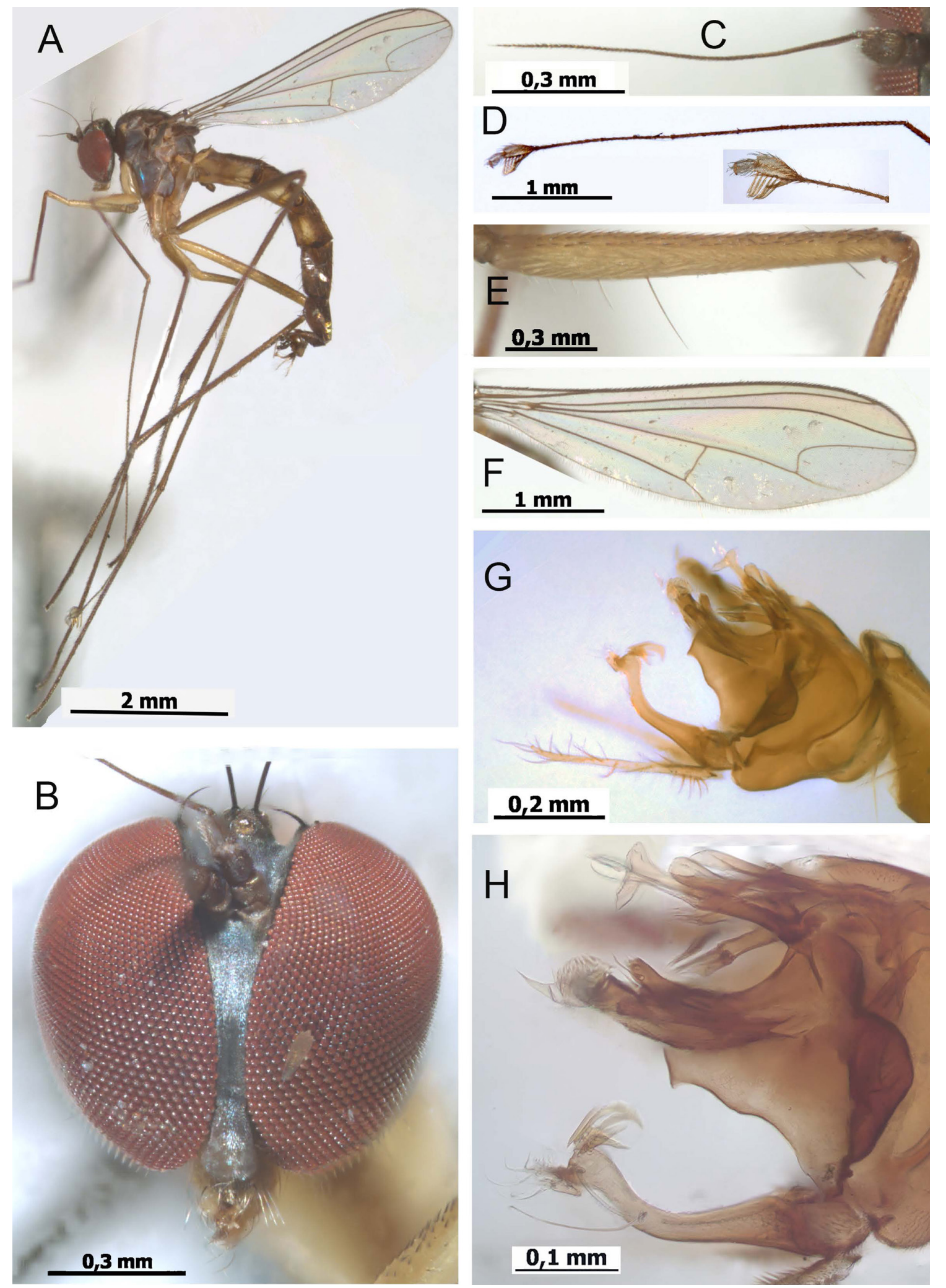

Fig. 9. Amblypsilopus fianarantsoa sp. nov. Holotype, $\widehat{\partial}$ (SMNHTAU). A. Habitus. B. Head. C. Antenna. D. Fore tarsus, with inset showing segments 3-5, dorsal view. E. Mid femur. F. Wing. G. Hypopygium, left lateral view, reflected light. H. Distoventral appendages of hypopygium, lateral view, transmitted light. 
THORAX. Mesonotum and scutellum metallic blue-green, weakly pollinose; pleura bronze-green, grey pollinose; metepimeron brownish; 6 dorsocentral bristles gradually decreasing in size anteriorly with strongest posterior pair; acrostichals short, biserial; scutellum with 2 strong bristles and 2 minute hairs laterally.

Legs. Mostly yellow; coxae yellow but mid coxa orange at base; fore and mid tarsi brownish to brown; segment 4 of fore tarsus yellowish white; segment 5 of fore tarsus silvery white (Fig. 9D); hind femur brownish on distal half dorsally; hind tibia brownish; hind tarsus brown to black; fore and mid coxae with dark hairs and 2 black subapical setae; hind coxa with 1 black seta at middle; fore and hind femora without strong or long setae; mid femur (Fig. 9E) with long fine ventral seta in middle, two times as long as height of femur, with 3-4 ventral hairs on basal half, about half as long as height of femur, with small posteroventral subapical seta; fore tibia without conspicuous setae; fore basitarsus long, without setae; segment 4 laterally flattened and widened, 2.25 times as long as wide, with posterior comb of 8-9 long yellow flattened setae, longer than width of segment (Fig. 9D); mid tibia with 2 short anterodorsals and 2 short posterodorsals, without conspicuous ventral setae; mid and hind tarsi simple, cylindrical; hind tibia with several short dorsal and ventral setae; femur, tibia and tarsomere (from first to fifth) length ratio $(\mathrm{mm})$ : fore leg: 1.28/1.79/3. 62/0.56/0.57/0.27/0.14, mid leg: 1.39/2.93/2.47/0.6/0.34/0.24/0.11, hind leg: 2.17/3.21/1.48/0.65/0.35/0.19/0.12.

WING (Fig. 9F). Widened distally, almost hyaline, veins brown; $\mathrm{R}_{4+5}$ gently curved to $\mathrm{M}_{1}$ in apical third; $M_{1+2}$ straight in basal half, slightly convex anteriad in middle part; $M_{1}$ with strong elbow, forming right angle with $\mathrm{M}_{1+2}$; ratio of parts of costa between $\mathrm{R}_{2+3}$ and $\mathrm{R}_{4+5}$ to those between $\mathrm{R}_{4+5}$ and $\mathrm{M}_{1}, 4 / 1$; crossvein $\mathrm{dm}$-m straight; ratio of crossvein $\mathrm{dm}-\mathrm{m}$ to apical part of $\mathrm{M}_{1+2}$ (fork-handle) to apical part of $\mathrm{M}_{4}, 33 / 76 / 24$; anal vein and lobe reduced; anal angle absent; lower calypter brownish, with fine yellow cilia; halter yellow with brown knob.

ABDOMEN. Thin and long, mostly shining dark brown, with short black hairs and marginal setae; segment 1 mostly yellow, with white and dark hairs; segments $2-4$ each with yellow lateral spot; pregenital segments combined 3.2 times as long as mesonotum; hypopygium (Fig. 9G) brown, with brown appendages; cercus yellow, brown at base, bifurcated from base; dorsal arm as long as epandrium, filiform, widened at base, sparsely covered with long setae along entire length, densely covered with numerous setulae at base; ventral arm of cercus shorter and thicker, thickened at base, with several remarkable apical setae, i.e., 3 thick apicoventral setae directed basally, one very long seta at base of small apicodorsal process covered with several short and long hairs (Fig. 9H); ventral arms of cerci fused almost to apex; surstylus projected, bilobed, with long thin arms; dorsal arm of surstylus with 2 short leaflike setae and tuft of short hairs at apex; epandrial lobe projected, trilobed; each lobe narrow, with pair of long flattened setae; outer lobe with especially long setae, with each seta remarkably widened at apex (Fig. 9H).

\section{Female}

Unknown.

Amblypsilopus freidbergi sp. nov.

urn:1sid:zoobank.org:act:EFAF1461-1455-4045-9E80-891385BF1760

Fig. 10

\section{Diagnosis}

Having all coxae entirely yellow and fore tibia with a long modified posterior seta, Amblypsilopus freidbergi sp. nov. keys to A. pallidicornis, which differs from the new species in the antenna yellow; the fore tibia as long as the basitarsus; the face broad, about three times as wide as the postpedicel; the fore basitarsus ventrally at base with cluster of very short bristlets and one longer and stronger black bristle. 
The antenna is black in $A$. freidbergi sp. nov., the fore tibia is $7 / 10$ as long as the basitarsus; the face is narrow, about as wide as the postpedicel; the fore tarsus has segment 4 black, segment 5 silvery white; the fore basitarsus is thin and long, with long white ventral hairs on basal 1/5.

\title{
Etymology
}

The species is named for the collector of the types, Dr Amnon Freidberg (SMNHTAU).

\section{Material examined}

\section{Holotype}

MADAGASCAR • ${ }^{\wedge}$; Andasibe, Analamazaotra Forest; $18^{\circ} 46^{\prime} \mathrm{S}, 48^{\circ} 24^{\prime}$ E; 950 m a.s.1.; 31 Oct. -4 Nov. 2007; A. Freidberg leg.; SMNHTAU.

\section{Paratypes}

MADAGASCAR $・ 2 \hat{\jmath}$; same collection data as for holotype; SMNHTAU.

\section{Description}

\author{
Male (Fig. 10A)
}

MeAsurements. Body length 5-5.25 mm; antenna length $1 \mathrm{~mm}$; wing length $4.5 \mathrm{~mm}$; wing width $1.2 \mathrm{~mm}$.

HEAD (Fig. 10B). Frons black (lateral view), white pollinose; strong short anterior vertical and long postvertical bristles; upper postocular setae black, short; lateral postocular setae white, uniserial; ventral postcranium covered with irregular white hairs; face black, white pollinose (lateral view), narrow, about 4 times as high as wide under antennae, 12-15 times as high as wide at clypeus, at clypeus half as wide as postpedicel; clypeus small, slightly bulging; antenna (Fig. 10C) black, about as long as height of head; pedicel with short bristles, with one long dorsal bristle; postpedicel globular, as long as high, with short hairs; arista-like stylus dorsoapical, microscopically haired; length ( $\mathrm{mm}$ ) of scape, pedicel, postpedicel, stylus, 0.06/0.06/0.09/0.83; proboscis orange-yellow; palpus small, brown, with white and black hairs.

THorax. Mesonotum and scutellum metallic blue-green; pleura blackish brown, weakly pollinose; metepimeron yellow; 6 strong dorsocentral bristles gradually decreasing in size anteriorly with strongest posterior pair; acrostichals short, biserial, decreasing in size anteriorly, with strongest posterior pair at suture; scutellum with 2 strong bristles and 2 hairs laterally.

LEGs. Mostly yellow; coxae yellow; segment 4 of fore tarsus black; segment 5 of fore tarsus silvery white; last segments of mid and hind tarsi brown; fore and mid coxae with light and dark hairs and 2-3 black subapical setae; hind coxa with 1 black seta at middle; femora without strong or long setae; fore tibia with long apicoventral light bristle, nearly three times as long as width of tibia; fore basitarsus thin and long, with long white ventral hairs on basal 1/5, two times as long as width of segment (Fig. 10D); segments 4-5 slightly thickened, segment 4 with black elongate setulae; segment 5 with white elongate setulae (Fig. 10E); mid tibia with 2 anterodorsals and 2 short posterodorsals, without conspicuous ventral setae; mid and hind tarsi simple, cylindrical; hind tibia with several short dorsal and ventral setae; femur, tibia and tarsomere (from first to fifth) length ratio $(\mathrm{mm})$ : fore leg: 1.29/1.79/3.06/0.58/0.41/0.26/0.14, mid leg: 1.45/2.92/2.13/0.4/0.25/0.18/0.13, hind leg: 2.09/3.22/1.37/0.59/0.34/0.21/0.15.

WING (Fig. 10F). Widest at middle, almost hyaline, veins brown; $\mathrm{R}_{4+5}$ gently curved to $\mathrm{M}_{1}$ in apical third; $M_{1+2}$ inconspicuously sinuate in basal half, slightly convex anteriad in middle part; $M_{1}$ with strong elbow, forming right angle with $\mathrm{M}_{1+2}$; ratio of parts of costa between $\mathrm{R}_{2+3}$ and $\mathrm{R}_{4+5}$ to those between $\mathrm{R}_{4+5}$ and $\mathrm{M}_{1}$, 5/1; crossvein dm-m straight; ratio of crossvein $\mathrm{dm}$-m to apical part of $\mathrm{M}_{1+2}$ (fork-handle) to apical part of $\mathrm{M}_{4}, 0.46 / 0.79 / 0.19$; anal vein and lobe reduced; anal angle absent; lower calypter brownish, with fine brown cilia; halter yellow with brown knob. 
AвDOMEn. Elongate, mostly greenish blue, with short black hairs and marginal setae; tergite 1 yellow; tergites 2-5 each with large lateral yellow spot; pregenital segments combined two times as long as mesonotum; segment 7 short, semicircular, embracing basolateral sides of epandrium; segment 8 as a
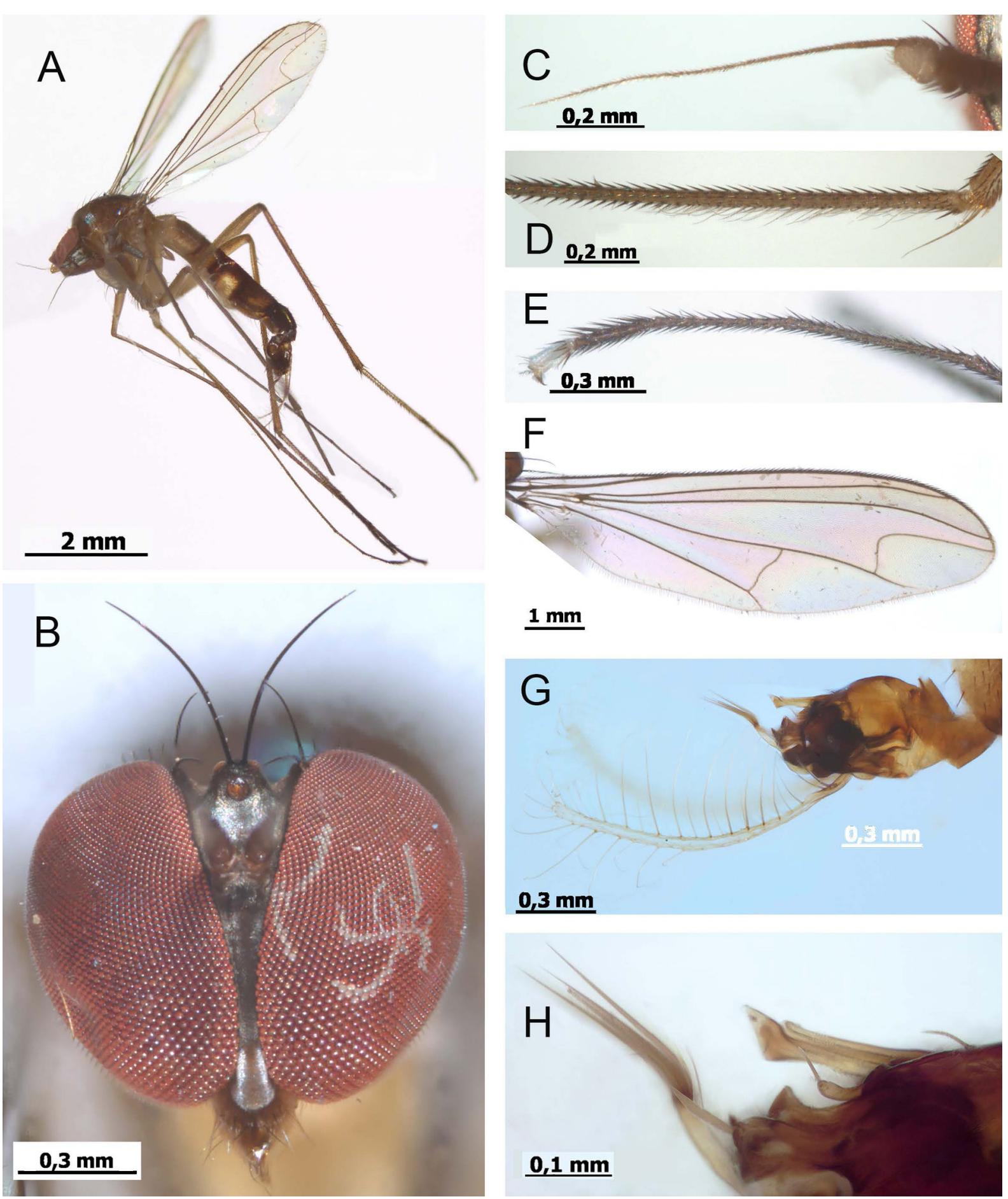

Fig. 10. Amblypsilopus freidbergi sp. nov. A-F. Holotype, § (SMNHTAU). G-H. Paratype, ð (SMNHTAU). A. Habitus. B. Head. C. Antenna. D. Fore basitarsus. E. Fore tarsomeres 2-5. F. Wing. G. Hypopygium, left lateral view, reflected light. H. Distoventral appendages of hypopygium, transmitted light. 
weak plate hidden under segment 7 and covering basal symmetrical foramen; hypopygium (Fig. 10G) brown, with brown appendages; hypandrium short, arising at apical third of epandrium, with 2 unequal arms; phallus thick, with subtriangular thickening at apex; cercus yellow, bifurcated from base; dorsal arm two times as long as epandrium, thin, flattened, slightly wider on basal half, covered with long hairs dorsally and apically, with lateral row of 12-14 long brownish setae along entire length; ventral arms of cerci fused to apex, S-shaped, mostly hidden by surstyli, projected ventrally; ventral arm of each cercus with 2 long thick apical bristles, as long as height of epandrium, and one shorter simple ventral subapical seta; surstylus strongly sclerotized, bilobed, with large flat rounded arms expanding distally, subequal in size, without remarkable setae; basal half of dorsal arm of surstylus concealed; large epandrial lobe projected distally, with one long thick apical bristle, strong spine-like inner process at apex, big subtriangular ventral subapical projection bearing 2 simple setae; small finger-like lobe at base of distoventral epandrial lobe, with 2 apical setae; 1 epandrial seta at base of hypandrium (Fig. 10H).

\title{
Female
}

Unknown.

\author{
Amblypsilopus leonidi sp. nov. \\ urn:1sid:zoobank.org:act:7436C062-7C49-4E10-BBB7-D9C511C8D7BD
}

Fig. 11

\section{Diagnosis}

Amblypsilopus leonidi sp. nov. is close to A. andasibensis sp. nov. and A. olgae sp. nov. in habitus. The last two species differ from $A$. leonidi sp. nov. in the fore tarsomeres 4-5 white or tarsomere 5 entirely white, and the male cercus with a strongly projected median lobe. The fore tarsomeres 4-5 are entirely black in A. leonidi sp. nov.; the cercus has median and ventral lobes subequal in length.

\section{Etymology}

The species name is dedicated to Leonid Grichanov, one of my grandsons (St. Petersburg, Russia).

\section{Material examined}

Holotype

MADAGASCAR • ${ }^{\lambda}$; Andasibe, Analamazaotra Forest; $18^{\circ} 46^{\prime}$ S, 48 $44^{\circ}$ E; 950 m a.s.1.; 31 Oct. 4 Nov. 2007; A. Freidberg leg.; SMNHTAU.

\section{Paratypes}

MADAGASCAR • $6 \hat{\partial}$; ; same collection data as for holotype; SMNHTAU.

\section{Description}

Male (Fig. 11A)

MEASUREMENTs. Body length $6.3 \mathrm{~mm}$; antenna length $1.3 \mathrm{~mm}$; wing length $5.2 \mathrm{~mm}$; wing width $1.2 \mathrm{~mm}$.

HEAD (Fig. 11B). Frons black, white pollinose; strong short anterior vertical and long postvertical bristles; upper postocular setae black, short; lateral postocular setae white, uniserial; ventral postcranium covered with irregular white hairs; face densely silvery-white pollinose, narrow, 4.5 times as wide under antennae, 9 times as high as wide at clypeus, at clypeus as wide as postpedicel; clypeus small, slightly bulging; antenna (Fig. 11C) with scape and pedicel dirty yellow, postpedicel orange on basal half and brown distally, 1.7 times as long as height of head; pedicel with short bristles, with one long dorsal bristle; postpedicel ovate, 1.3 times as long as high, with short hairs; arista-like stylus dorsal, microscopically haired; length $(\mathrm{mm})$ of scape, pedicel, postpedicel, stylus, $0.08 / 0.08 / 0.11 / 1.04$; proboscis orange; palpus blackish, with white and brown hairs. 
THorax. Mesonotum orange, with brown, shining greenish blue, medial stripe expanding posteriorly; scutellum metallic blue; pleura yellow, weakly pollinose; 6 strong dorsocentral bristles gradually
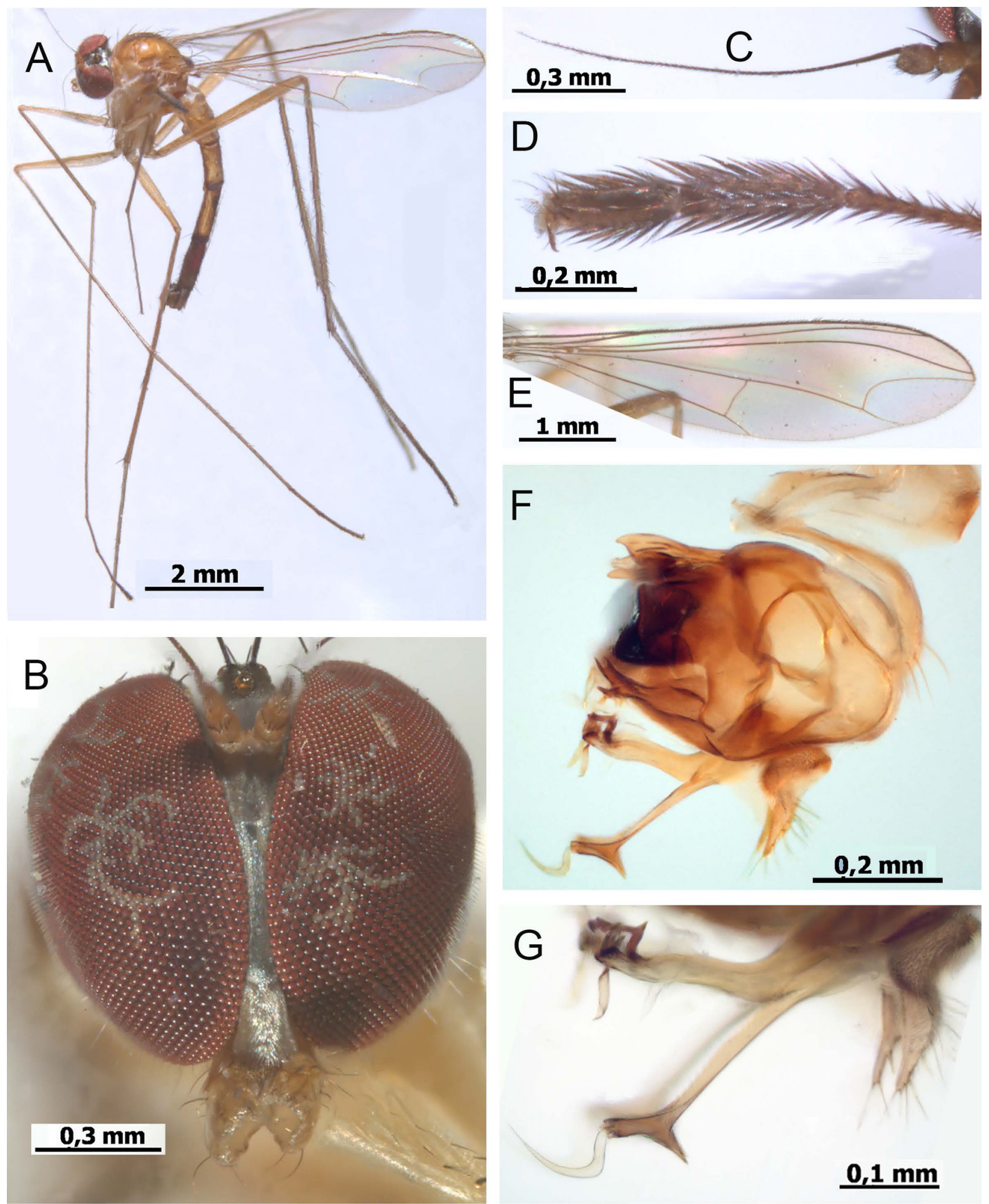

Fig. 11. Amblypsilopus leonidi sp. nov. A-E. Holotype, $\diamond$ (SMNHTAU). F-G. Paratype, $\widehat{\partial}$ (SMNHTAU). A. Habitus. B. Head. C. Antenna. D. Fore tarsomeres 4-5. E. Wing. F. Hypopygium, left lateral view, reflected light. G. Cercal lobes, lateral view, transmitted light. 
decreasing in size anteriorly with strongest posterior pair; acrostichals short, biserial; scutellum with 2 strong bristles and 2 hairs laterally.

LEGs. Mostly yellow; coxae yellow; tarsi brown from tip of basitarsus; segments 4 and 5 of fore tarsus black; fore and mid coxae with light and dark hairs and 2-3 black subapical setae; hind coxa with 1 black seta at middle; femora without strong or long setae; fore tibia without conspicuous setae; fore basitarsus thin and long, with 6 short ventral setae, two times as long as width of segment; segments 4-5 flattened dorsoventrally, slightly widened, with black flattened setae laterally, longer than tarsomere width (Fig. 11D); mid tibia with one short anterodorsal and two short posterodorsals, without conspicuous ventral setae; mid and hind tarsi simple, cylindrical; hind tibia with several short dorsal and ventral setae; femur, tibia and tarsomere (from first to fifth) length ratio $(\mathrm{mm})$ : fore leg: 1.43/2.08/5.21/0.55/0.6/0.26/0.2, mid leg: 1.77/4 .13/3.27/0.63/0.41/0.22/0.17, hind leg: 2.83/4.68/2.06/0.74/0.43/0.22/0.16.

WING (Fig. 11E). Widened distally, almost hyaline, veins brown; $R_{4+5}$ gently curved to $M_{1}$ in apical third; $\mathrm{M}_{1+2}$ straight in basal half, slightly convex anteriad in middle part; $\mathrm{M}_{1}$ with strong elbow, forming right angle with $\mathrm{M}_{1+2}$; ratio of parts of costa between $\mathrm{R}_{2+3}$ and $\mathrm{R}_{4+5}$ to those between $\mathrm{R}_{4+5}$ and $\mathrm{M}_{1}, 6 / 1$; crossvein dm-m straight; ratio of crossvein dm-m to apical part of $\mathrm{M}_{1+2}$ (fork-handle) to apical part of $\mathrm{M}_{4}, 0.43 / 1.24 / 0.31$; anal vein and lobe reduced; anal angle absent; lower calypter brownish, with fine brown cilia; halter yellow with brown knob.

ABDOMEN. Thin and long, mostly orange-yellow, brown along distal margin of tergite 2 and along dorsal side of tergites 3-6, with short black hairs and marginal setae; pregenital segments combined nearly three times as long as mesonotum; hypopygium (Fig. 11F) brown, with brown to black appendages; cercus (Fig. 11G) brown, trilobed; dorsal arm short, half as long as epandrium, thick at base, narrow distally, densely covered with numerous setulae at base, with long dark setae along narrow part; median lobe of cercus as long as epandrium, thin, with triangular subapical dorsal process and one long flat falcate seta; ventral arm of cercus as long as epandrium, thicker than median lobe, with one long flat subapical seta directed distally, 3 short thick apicoventral setae directed basally, one long thick subapical L-shaped process; arms of cerci fused at base; surstylus bilobed, with sclerotized arms; dorsal arm of surstylus thin, with 2 pointed apical processes and 2 subapical processes ending with long thick seta each; ventral arm of surstylus broad, curved towards median axis of epandrium, bearing 3 long strong bristles at apex; epandrial lobe projected, sclerotized, with 1 apical and 2 ventral short setae; 1 epandrial seta at base of epandrial lobe.

\title{
Female
}

Unknown.

\author{
Amblypsilopus olgae sp. nov. \\ urn:1sid:zoobank.org:act:06A4A8A3-6A63-4EBF-BA25-4DA0E45A1AA9
}

Fig. 12

\section{Diagnosis}

Amblypsilopus olgae sp. nov. is very close to A. andasibensis sp. nov. in habitus. The latter differs from the new species in the fore tarsomere 4 entirely black, tarsomere 5 white. The fore tarsomeres $4-5$ are entirely white in A. olgae sp. nov.; the long lobe of the cercus ends with one long and one short thick setae, but no long setae at middle.

\section{Etymology}

The species name is dedicated to Olga Grichanova, a member of my family (St. Petersburg, Russia). 


\section{Material examined}

\section{Holotype}

MADAGASCAR • ${ }^{\wedge}$; Andasibe, Analamazaotra Forest; $18^{\circ} 46^{\prime} \mathrm{S}, 48^{\circ} 24^{\prime}$ E; 950 m a.s.1.; 31 Oct. 4 Nov. 2007; L. Friedman leg.; SMNHTAU.

\section{Description}

\section{Male}

MeAsurements. Body length $5.7 \mathrm{~mm}$; antenna length $1.2 \mathrm{~mm}$; wing length $4.8 \mathrm{~mm}$; wing width $1.2 \mathrm{~mm}$.

HEAD (Fig. 12A). Frons black, white pollinose; strong short anterior vertical and long postvertical bristles; upper postocular setae black, short; lateral postocular setae white, uniserial; ventral postcranium covered with irregular white hairs; face densely silvery-white pollinose, narrow, 3.8 times as high as wide under antennae, 8.7 times as high as wide at clypeus, at clypeus nearly as wide as postpedicel; clypeus small, slightly bulging; antenna (Fig. 12B) with scape and pedicel dirty yellow, postpedicel orange on basal half and brown distally, 1.3 times as long as height of head; pedicel with short bristles, with one long dorsal bristle; postpedicel ovate, 1.1 times as long as high, with short hairs; arista-like stylus dorsal, microscopically haired; length $(\mathrm{mm})$ of scape, pedicel, postpedicel, stylus, 0.08/0.07/0.1/0.99; proboscis orange; palpus blackish, with white and brown hairs.

THORAX. Mesonotum orange, with brown, shining greenish blue, medial stripe expanding posteriorly; scutellum metallic blue; pleura yellow, weakly pollinose; 6 strong dorsocentral bristles gradually decreasing in size anteriorly with strongest posterior pair; acrostichals short, biserial; scutellum with 2 strong bristles and 2 hairs laterally.

Legs. Mostly yellow; coxae yellow; tarsi brown from tip of basitarsus; segments 4 and 5 of fore tarsus white (Fig. 12C); fore and mid coxae with light and dark hairs and 2-3 black subapical setae; hind coxa with 1 black seta at middle; femora without strong or long setae; fore tibia without conspicuous setae; fore basitarsus thin and long, with 6 short ventral setae, two times as long as width of segment; segments 4-5 flattened dorsoventrally, slightly widened, with black flattened setae laterally, longer than tarsomere width; mid tibia with one short anterodorsal and two short posterodorsals, without conspicuous ventral setae; mid and hind tarsi simple, cylindrical; hind tibia with several short dorsal and ventral setae; femur, tibia and tarsomere (from first to fifth) length ratio $(\mathrm{mm}$ ): fore leg: $1.33 / 1.69 / 3.83 / 0.7 / 0.54 / 0.22 / 0.13$, mid leg: $1.55 / 3.12 / 2.19 / 0.63 / 0.39 / 0.21 / 0.13$, hind leg: $2.37 / 3.77 / 1.46 / 0.75 / 0.4 / 0.23 / 0.13$.

WING (Fig. 12D). Widened distally, almost hyaline, veins brown; $R_{4+5}$ gently curved to $M_{1}$ in apical third; $\mathrm{M}_{1+2}$ straight in basal half, slightly convex anteriad in middle part; $\mathrm{M}_{1}$ with strong elbow, forming right angle with $\mathrm{M}_{1+2}$; ratio of parts of costa between $\mathrm{R}_{2+3}$ and $\mathrm{R}_{4+5}$ to those between $\mathrm{R}_{4+5}$ and $\mathrm{M}_{1}, 4.5 / 1$; crossvein dm-m straight; ratio of crossvein dm-m to apical part of $\mathrm{M}_{1+2}$ (fork-handle) to apical part of $\mathrm{M}_{4}, 0.47 .1 .07 / 0.44$; anal vein and lobe reduced; anal angle absent; lower calypter brownish, with fine brown cilia; halter yellow with brown knob.

AвDOMEN. Thin and long, mostly orange-yellow, brown along distal margin of tergite 2 and along dorsal side of tergites 3-6, with short black hairs and marginal setae; pregenital segments combined three times as long as mesonotum; hypopygium (Fig. 12E) brown, with brown to black appendages; hypandrium short, with reduced arms; cercus (Fig. 12F) brown, bifurcated from base; dorsal lobe partly concealed, flat, subtriangular, half as long as epandrium, with pointed apex, sparsely covered with long dark setae along entire length, densely covered with numerous setulae at base; ventral arms of cerci fused at base, as long as epandrium; ventral arm of each cercus directed ventrally, bifurcated from point of fusion, with long thin distal lobe ending with one long and one short thick setae; proximal lobe of ventral arm thick, with ventral series of setae on distal half, beginning with very long thick curved seta at middle, 
then about 5 short thick setae, ending with 3-4 very long simple setae; surstylus projected, bilobed, with irregularly curved broad flat arms; dorsal arm of surstylus with small process at apex; ventral arm of surstylus larger and stronger sclerotized than dorsal arm, with small spine at base, with pointed subapical projection and 3 big and thick apical setae; epandrial lobe simple, projected, sclerotized; 2 long epandrial setae at base of epandrial lobe.

Female

Unknown.
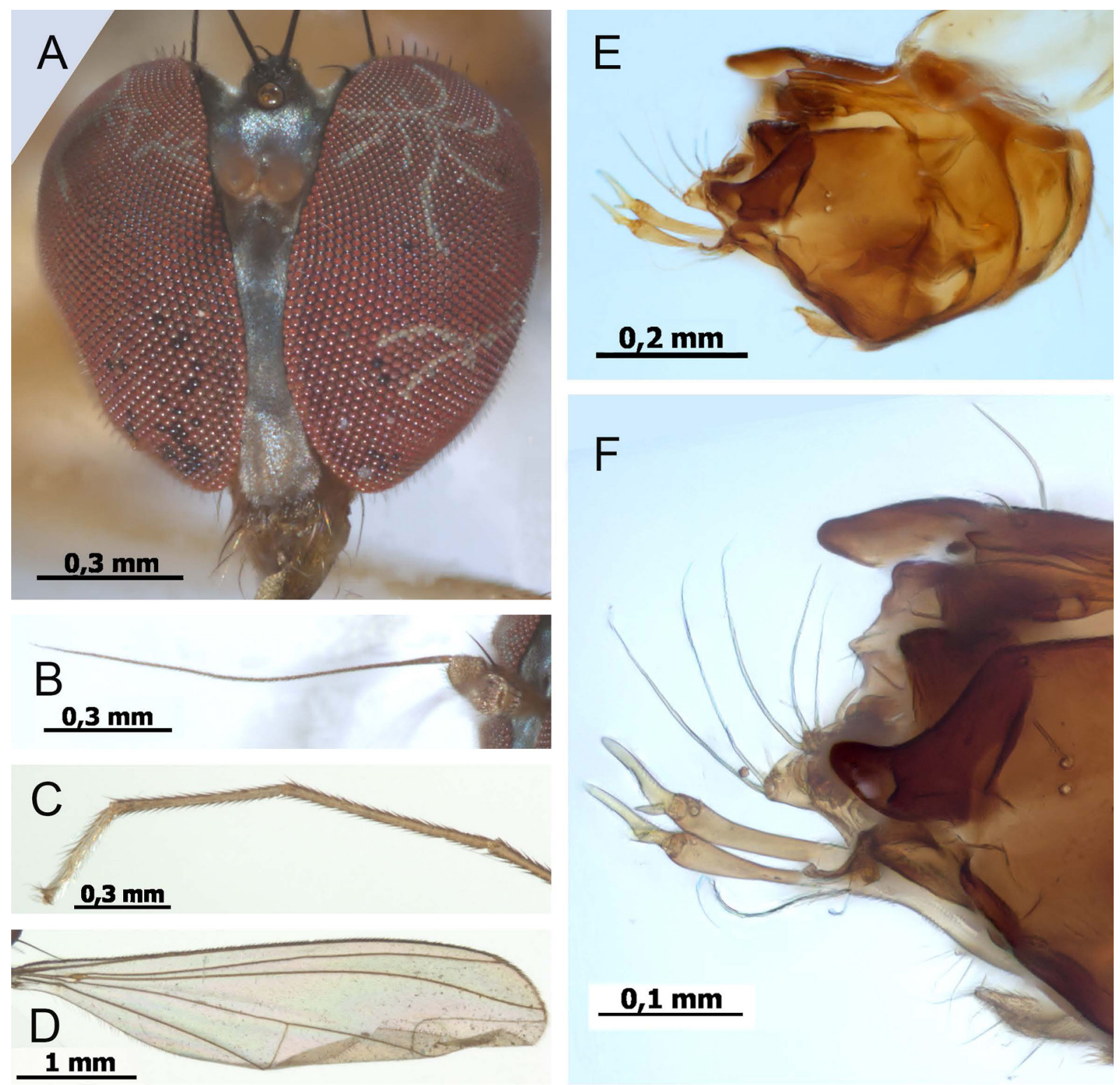

Fig. 12. Amblypsilopus olgae sp. nov. Holotype, ${ }^{\lambda}$ (SMNHTAU). A. Head. B. Antenna. C. Fore tarsomeres 2-5. D. Wing. E. Hypopygium, left lateral view, reflected light. F. Distal appendages of hypopygium, transmitted light. 
Amblypsilopus stuckenbergi (Vanschuytbroeck, 1957)

Sciapus stuckenbergi Vanschuytbroeck, 1957: 3. Type locality: Madagascar: Perinet.

Amblypsilopus stuckenbergi-Bickel 1994: 373.

\section{Diagnosis}

Amblypsilopus stuckenbergi forms a group of Madagascan species with narrow male face and relatively short antennae. Body length 3-4 mm. Face silvery white pollinose, in middle half as wide as face under antennae; clypeus slightly bulging; thorax and abdomen mostly yellow; wing venation unmodified; wing anal lobe and vein absent; legs including coxae yellow; segment 3 of fore tarsus two times as long as segment 2, with 1-2 long dorsoapical setae, longer than segment 4; segments 4 and 5 of fore tarsus flattened; fore femur, tibia and tarsomere (from first to fifth) length ratio: 13/16/25/5/10.5/1/1 (other legs have no diagnostic characters); cercus with 2 long dorsal setae.

\section{Material examined}

\section{Holotype}

MADAGASCAR・ ○; Périnet; Dec. 1955; M.B. Stuckenberg leg.; NMSA.

\section{Distribution}

Madagascar (Alaotra-Mangoro).

\section{Discussion}

Now almost all (93\%) of the known Madagascan and Mascarene species of Amblypsilopus are endemic to their islands. As for the described taxa of Diptera Linnaeus, 1758, Irwin et al. (2003) estimated that $14 \%$ of the genera and nearly $80 \%$ of the species of flies that occur in Madagascar were endemic to that island. Keeping in mind many poorly known dipteran families in the Madagascan fauna, I think the endemism is much higher there. Regarding Dolichopodidae, Dyte \& Smith (1980) listed 18 mainly endemic Madagascan species and about the same number of doubtful records of Palaearctic and continental African species from that island. Kirk-Spriggs \& Stuckenberg (2009) mentioned 52 Madagascan species (7\% of the Afrotropical fauna), and Grichanov (2018) included 75 Madagascan species in his Catalog (nearly 10\% of the Afrotropical fauna). Now, 87 dolichopodid species are known from the island, with about 10 'tramp' species widely distributed across the Indian Ocean. So, nearly $90 \%$ of those species are endemic to Madagascar. I think the estimated number of species of the family is $300-400$.

Presently, ca 60 species of Amblypsilopus are known from the Afrotropical Region, and 25 species are known from Madagascar. The Madagascan fauna of the genus is now the most diverse in the Afrotropics and one of the most diverse among local island faunas in the World. Most of the species of Madagascar and adjacent islands are known only from their type localities. According to labels cited under the published material, almost all Madagascan species (except A. pallidicornis) inhabit humid and subhumid forests in the mountainous areas, collected mainly in the island's protected natural areas, from the Montagne des Français Reserve and the Ankarana Reserve in the North to the Tolagnaro (=Fort Dauphin) District in the South. The small Analamazaotra Reserve in the Centre of humid eastern Madagascar with its primary growth forest is especially diverse. Drs A. Freidberg and L. Friedman collected eleven species of Amblypsilopus (including ten new species described in this paper) during their six-day visit there (Fig. 13). The Morarano Chrome locality near the Lake Alaotra situated in the same Alaotra-Mangoro Region on the island's northern central plateau numbers three species of Amblypsilopus. Four species of the genus are known now from the Ranomafana National Park (southward of the Analamazaotra 


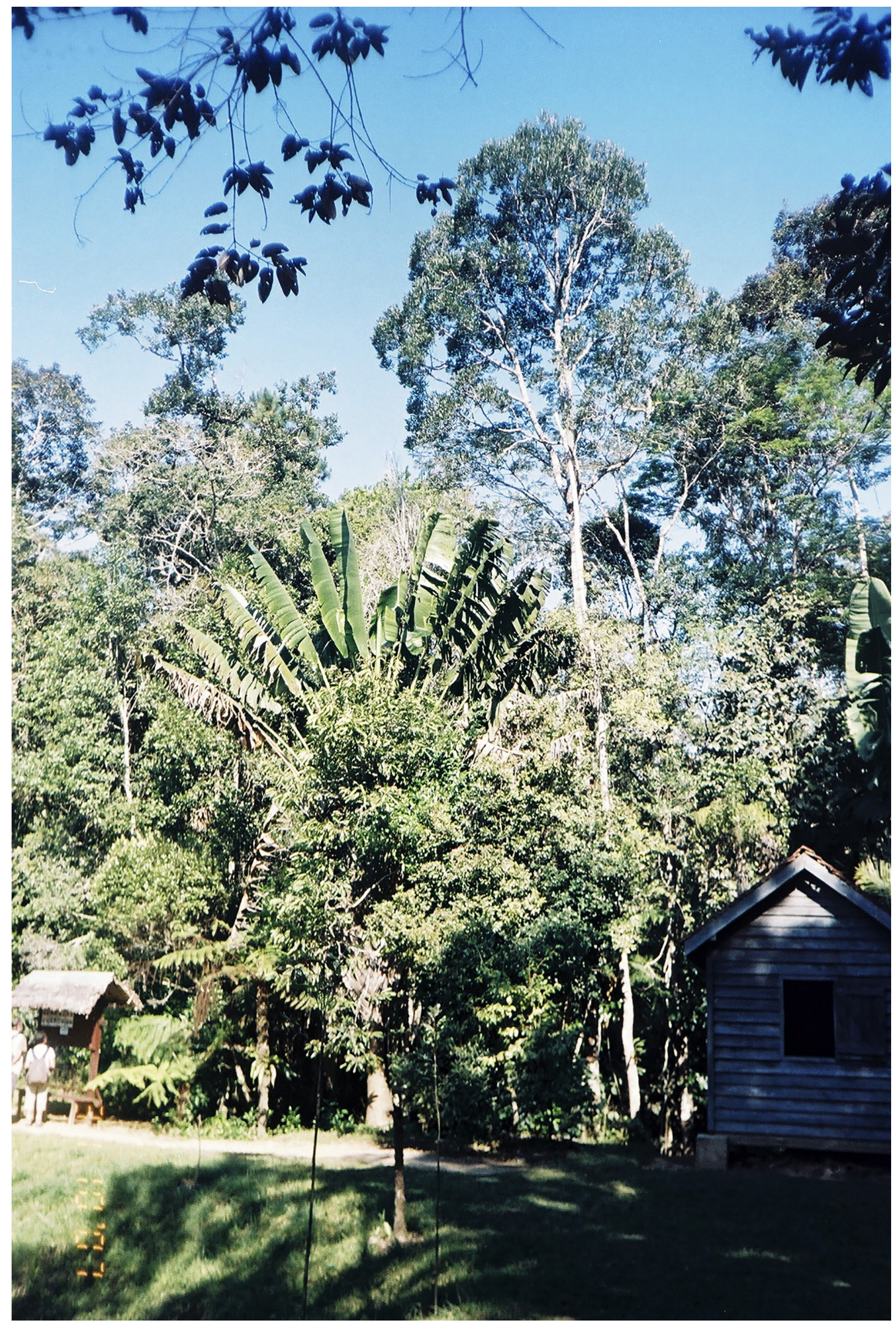

Fig. 13. Damp forest at the Feon'Ny Ala Hôtel beside the Analamazaotra Special Reserve. Photo by courtesy of Dr Leonid Friedman (SMNHTAU). 
Reserve). The other collection sites have only one or two species. It seems that only transoceanic $A$. pallidicornis inhabits the coastal line of northeastern Madagascar (a lagoon near Mahavelona, commonly called Foulpointe, in the region of Atsinanana).

Most species of Madagascan Amblypsilopus are distinct, with modified male fore tarsus, often with thin elongated tarsomeres 1 and 2, sometimes with fore tarsomeres 4-5 flattened, white or bearing long hairs, with remarkable setae on some podomeres. Bickel (1994) mentioned two Madagascan species in his review. Amblypsilopus pallidicornis forms the Indo-Pacific Amblypsilopus pallidicornis group, and A. flabellifer is associated with the A. abruptus group widespread throughout the Old World tropics. Grichanov (1996) separated the A. auratus group of Afrotropical species (including A. madagascariensis and A. cilifrons). Males of 28 species of Madagascar and adjacent islands are very diverse morphologically, with MSSC sometimes similar to characters used by Bickel (1994) for the definition of many species groups. However, they cannot be associated with confidence with Oriental and Australasian species groups except for the A. abruptus group (=A. auratus group). The other species provisionally belong to the Amblypsilopus pallidicornis group with rather broad male face and elongate antennae and to the $A$. stuckenbergi group with relatively narrow male face and relatively short antennae (see above).

As a result of research from 1996 to 2020, the number of species of the genus has increased from three to 28 valid names known from Madagascar and adjacent islands. The real number of species of Amblypsilopus may reach here at least 50.

\section{Acknowledgements}

The author is sincerely grateful to Drs Ashley H. Kirk-Spriggs (presently at the Natural History Museum, London, UK), Mike Mostovsky and Amnon Freidberg (SMNHTAU) for providing the specimens studied in this research. The work was funded by RFBR and NSFC according to the research project No. 20-5453005. The comparative analysis of morphological characters and the preparation of illustrations were performed within the Program for Basic Scientific Research of the Government of the Russian Federation, project No. 0665-2020-0014. Drs Renato Capellari (Instituto Federal do Triângulo Mineiro, Uberaba, Minas Gerais, Brazil) and Dan Bickel (Australian Museum, Sydney, Australia) kindly commented on earlier drafts of the manuscript.

\section{References}

Becker T. 1923. Dipterologische Studien. Dolichopodidae. D. Aethiopische Region. Entomologische Mitteilungen 12: 1-50.

Bickel D.J. 1994. The Australian Sciapodinae (Diptera: Dolichopodidae), with a review of the Oriental and Australasian faunas, and a world conspectus of the subfamily. Records of the Australian Museum Supplement 21: 1-394. https://doi.org/10.3853/j.0812-7387.21.1994.50

Bickel D.J. 2009. Amblypsilopus (Diptera: Dolichopodidae: Sciapodinae) from the Southwest Pacific, with a focus on the radiation in Fiji and Vanuatu. In: Evenhuis N.L. \& Bickel D.J. (eds) Fiji Arthropods XIII. Bishop Museum Occasional Papers 103: 3-61.

Bickel D.J. 2019. The Amblypsilopus amnoni and megastoma groups in New Guinea (Diptera: Dolichopodidae: Sciapodinae). Israel Journal of Entomology 49 (2): 195-214. https://doi.org/10.5281/zenodo.3522860

Cumming J.M. \& Wood D.M. 2017. 3. Adult morphology and terminology: 89-134. In: KirkSpriggs A.H. \& Sinclair B.J. (eds) Manual of Afrotropical Diptera. Volume 1. Introductory Chapters and Keys to Diptera Families. Suricata 4. SANBI Graphics \& Editing, Pretoria. 
Dyte C.E. \& Smith K.G.V. 1980. 33. Family Dolichopodidae: 443-463. In: Crosskey R.W. (ed.) Catalogue of the Diptera of the Afrotropical Region. British Museum (Natural History), London.

Grichanov I.Ya. 1996. Four new species of the genus Amblypsilopus Bigot (Diptera: Dolichopodidae) from Tropical Africa and Papua New Guinea. International Journal of Dipterological Research 7 (4): 285-294.

Grichanov I.Ya. 1998. New data on Sciapodinae (Diptera: Dolichopodidae) with a revised catalogue and keys to afrotropical species. Bulletin de l'Institut royal des Sciences naturelles de Belgique, Entomologie 68: 79-130.

Grichanov I.Ya. 1999. New species and new records of afrotropical Sciapodinae (Diptera: Dolichopodidae). Bulletin de l'Institut royal des Sciences naturelles de Belgique, Entomologie 69: 113135.

Grichanov I.Ya. 2003. New Afrotropical Sciapodinae (Diptera: Dolichopodidae) with some new synonymy. Russian Entomological Journal 12: 329-346.

Grichanov I.Ya. 2017. Alphabetic List of Generic and Specific Names of Predatory Flies of the Epifamily Dolichopodoidae (Diptera). $2^{\text {nd }}$ Ed. All-Russian Institute of Plant Protection, St. Petersburg.

https://doi.org/10.5281/zenodo.884863

Grichanov I.Ya. 2018. An Annotated Catalogue of Afrotropical Dolichopodoidae (Diptera). All-Russian Institute of Plant Protection, St. Petersburg. https://doi.org/10.5281/zenodo.1187006

Grichanov I.Ya. \& Brooks S.E. 2017. 56. Dolichopodidae (long-legged dance flies): 1265-1320. In: Kirk-Spriggs A.H. \& Sinclair B.J. (eds) Manual of Afrotropical Diptera, Volume 2. Nematocerous Diptera and Lower Brachycera. Suricata 5. SANBI Graphics \& Editing, Pretoria.

Hardy D.E. \& Kohn M.A. 1964. Dolichopodidae. In: Zimmerman E.C. (ed.) Insects of Hawaii 11: $13-256$.

Irwin M.E. 1974. An account of southern African genus Sciopolina with descriptions of new species (Diptera: Dolichopodidae: Sciapodinae). Annals of the Natal Museum 22: 221-264.

Irwin M.E., Schlinger E.I. \& Thompson F.C. 2003. Diptera, True Flies: 692-702. In: Goodman S.M. \& Benstead J.P. (eds) The Natural History of Madagascar. University of Chicago Press, Chicago \& London.

Kirk-Spriggs A.H. \& Stuckenberg B.R. 2009. Afrotropical Diptera - rich savannas, poor rainforests: 155-196. In: Pape T., Bickel D. \& Meier R. (eds) Diptera Diversity: Status, Challenges and Tools. Brill Academic Publishers, Leiden \& Boston. https://doi.org/10.1163/ej.9789004148970.I-459.31

Lamb C.G. 1922. The Percy Sladen Trust expedition to the Indian Ocean in 1905 under the leadership of Mr. J. Stanley Gardiner, M.A. Volume 7. No. VIII. - Diptera: Asilidae, Scenopinidae, Dolichopodidae, Pipunculidae, Syrphidae. Transactions of the Linnean Society of London (2) (Zoology) 18: 361-416. https://doi.org/10.1111/j.1096-3642.1922.tb00554.x

Meuffels H. \& Grootaert P. 2007. New longlegged flies (Diptera, Dolichopodidae) of the Seychelles. Phelsuma 15: 28-62.

Meuffels H.J.G. \& Grootaert P. 2009. Family Dolichopodidae: 117-143. In: Gerlach J. (ed.) The Diptera of the Seychelles Islands. Pensoft, Sofia.

Newsome D. \& Hassell S. 2014. Tourism and conservation in Madagascar: the importance of Andasibe National Park. Koedoe 56 (2): a1144 (1-8 pp.). https://doi.org/10.4102/koedoe.v56i2.1144

Rossi G. 1974. Morphologie et évolution d'un karst en milieu tropical: l'Ankarana. Mémoires et Documents du CNRS 15: 279-298. 
Vanschuytbrock P. 1952. Deux diptères dolichopodides malgaches. Naturaliste malgache 4 (1): 89-90.

Vanschuytbroeck P. 1957. Dolichopodidae de Madagascar (Diptera, Brachycera, Orthorrhapha). Bulletin de l'Institut royal des Sciences naturelles de Belgique 33 (25): 1-7.

Vanschuytbroeck P. 1962. Diptères dolichopodides africains. Revue de Zoologie et de Botanique africaines 65 (3-4): 352-355.

Manuscript received: 22 August 2020

Manuscript accepted: 4 December 2021

Published on: 18 June 2021

Topic editor: Nesrine Akkari

Section editor: Torbjørn Ekrem

Desk editor: Pepe Fernández

Printed versions of all papers are also deposited in the libraries of the institutes that are members of the EJT consortium: Muséum national d'histoire naturelle, Paris, France; Meise Botanic Garden, Belgium; Royal Museum for Central Africa, Tervuren, Belgium; Royal Belgian Institute of Natural Sciences, Brussels, Belgium; Natural History Museum of Denmark, Copenhagen, Denmark; Naturalis Biodiversity Center, Leiden, the Netherlands; Museo Nacional de Ciencias Naturales-CSIC, Madrid, Spain; Real Jardín Botánico de Madrid CSIC, Spain; Zoological Research Museum Alexander Koenig, Bonn, Germany; National Museum, Prague, Czech Republic. 